Illinois State University

ISU ReD: Research and eData

Theses and Dissertations

$10-21-2019$

\title{
High School Students Activities And Learning Experiences: Students' Views Of An Ipad Initiative
}

Susan E. Hess

Illinois State University, shess@d211.org

Follow this and additional works at: https://ir.library.illinoisstate.edu/etd

Part of the Elementary and Middle and Secondary Education Administration Commons, Instructional Media Design Commons, and the Secondary Education and Teaching Commons

\section{Recommended Citation}

Hess, Susan E., "High School Students Activities And Learning Experiences: Students' Views Of An Ipad Initiative" (2019). Theses and Dissertations. 1177.

https://ir.library.illinoisstate.edu/etd/1177

This Dissertation is brought to you for free and open access by ISU ReD: Research and eData. It has been accepted for inclusion in Theses and Dissertations by an authorized administrator of ISU ReD: Research and eData. For more information, please contact ISUReD@ilstu.edu. 


\title{
HIGH SCHOOL STUDENTS ACTIVITIES AND LEARNING EXPERIENCES: STUDENTS' VIEWS OF AN IPAD INITIATIVE
}

\author{
SUSAN E. HESS
}

\section{Pages}

With the increase of technology in classrooms today, school districts are using devices to prepare students to be literate in the digital world. Besides using computers, schools are introducing iPads as a way to give their students experiences with digital learning. One district embarked on a district-issued one-to-one iPad initiative in which every student was given an iPad to use for their academic and personal use. Despite iPads infiltrating high school classrooms, little research exists on the students' perspectives of the use of the iPad for personal and academic use and the impact they have on student learning. In this study, students were interviewed about their experiences with the iPads and observed using the iPads in class. After the observations, the students were interviewed in a follow-up interview in which the students shared a work sample that was created using the iPad. These students were studied to understand how they were using the iPads and how the devices impacted their learning in the digital age. Using the constructivist theory and the SAMA model as guides, this study found that the students not only enjoyed using the iPads but were also able to navigate their education to effectively learn using the iPads. Although most of their implementation was at the substitution level, some students have used the iPads for higher-level activities in which they could produce items at the redefinition level that were never thought possible years ago.

KEYWORDS: one-to-one learning; iPads; SAMR; students' perspectives 


\title{
HIGH SCHOOL STUDENTS ACTIVITIES AND LEARNING EXPERIENCES: \\ STUDENTS' VIEWS OF AN IPAD INITIATIVE
}

SUSAN E. HESS

\author{
A Dissertation Submitted in Partial \\ Fulfillment of the Requirements \\ for the Degree of \\ DOCTOR OF EDUCATION \\ School of Teaching and Learning \\ ILLINOIS STATE UNIVERSITY
}

2019 
(C) 2019 Susan E. Hess 


\section{HIGH SCHOOL STUDENTS ACTIVITIES AND LEARNING EXPERIENCES: \\ STUDENTS' VIEWS OF AN IPAD INITIATIVE}

SUSAN E. HESS

COMMITTEE MEMBERS:

Barbara B. Meyer, Chair

Brian Horn

Terry Husband 


\section{ACKNOWLEDGMENTS}

From the beginning, I knew the doctoral process would be difficult and would take a lot of perseverance, patience, and determination on my part. There are many people I have to thank for their support and guidance throughout this process. First, I would like to thank my dissertation committee, Dr. Barbara Meyer, Dr. Brian Horn, and Dr. Terry Husband for their willingness to meet with me and give me honest feedback. Their guidance was truly instrumental to my success. I am also so grateful for my chair Dr. Meyer for her enthusiasm and patience when I was at my wit's end. She gave me hope when I thought there was no hope left.

Additionally, I want to thank my family for the significant role they played in assisting me during the doctoral and dissertation process. I appreciate the continuous support and encouragement they gave me even when I was busy with class or schoolwork and would miss out on our family time. I especially want to thank my husband, Mark, and my daughters, Kylie and Haley, who were very proud of their mom and her accomplishments. I also need to thank my mom and dad, Mary Lou and Bill, who always asked for updates on my doctorate and would join my girls at their activities when I couldn't. I hope that this experience makes my parents proud and helps pave the way for my daughters to pursue their dreams as well.

I need to thank all of the wonderful colleagues and co-workers who have helped me along the way. I need to thank my previous principal, Tim, who encouraged me to join the doctoral cohort to pursue my degree. He was instrumental in his support and guidance as I started this process. He and my district administrators gave me an opportunity that I might not have otherwise started. I also need to thank my current principal, Julie, who helped support me with the time for student access and interviews. I greatly appreciate my district colleagues who were members of the doctoral cohort as they were sounding boards for ideas, questions, and 
support. I especially want to thank Danielle, Kerri, Octavio, and Christina for listening and giving me support, encouragement, and resources.

Finally, I want to thank the students at the schools in our district who were so willing to work with me. Although I talked with students from three different schools, these students were honest, helpful, and responsive to my meeting requests, questions, and emails. By interacting with these students and meeting students who were able to tell me about new activities they were doing with their iPads, I became truly amazed and invigorated as an educator and one-to-one instructor. These students were at the heart of this study, and I could not have done it without them.

S.E.H. 


\section{CONTENTS}

Page

ACKNOWLEDGMENTS

FIGURES

CHAPTER I: INTRODUCTION TO THE STUDY 1

Overview of the Issues 2

Research Questions $\quad 4$

Definition of Terms

Description of the Study $\quad 5$

$\begin{array}{ll}\text { Theoretical Perspective } & 7\end{array}$

$\begin{array}{ll}\text { Significance of the Study } & 8\end{array}$

$\begin{array}{ll}\text { Limitations } & 9\end{array}$

Overview of the Study 11

CHAPTER II: REVIEW OF LITERATURE 12

Benefits of iPads in the Classroom $\quad 13$

Increasing Reading Skills through Technology 14

Teaching Reading 16

Literacy: Digital Text Versus Traditional Text 17

$\begin{array}{ll}\text { Student Choice } & 20\end{array}$

$\begin{array}{ll}\text { Motivation } & 21\end{array}$

iPad Use in Higher Education 23

$\begin{array}{ll}\text { High School iPad Use } & 24\end{array}$

$\begin{array}{ll}\text { Junior High Use } & 26\end{array}$ 
Elementary Use

Reading Processes for Digital Reading Versus Traditional Reading 29

CHAPTER III: METHODOLOGY 39

Research Questions $\quad 39$

$\begin{array}{ll}\text { Research Design } & 40\end{array}$

Strengths and Limitations to Using Qualitative Methods $\quad 42$

$\begin{array}{ll}\text { Site for the Study } & 43\end{array}$

Participants of the Study $\quad 46$

$\begin{array}{ll}\text { Participant Profiles } & 47\end{array}$

$\begin{array}{ll}\text { Freshmen } & 47\end{array}$

$\begin{array}{lr}\text { Sophomores } & 48\end{array}$

Juniors $\quad 49$

$\begin{array}{ll}\text { Seniors } & 49\end{array}$

$\begin{array}{ll}\text { Data Collection } & 49\end{array}$

$\begin{array}{ll}\text { Interviews } & 49\end{array}$

Observations and Documentations $\quad 52$

Data Analysis $\quad 53$

Role of the Researcher and Positionality $\quad 60$

$\begin{array}{ll}\text { Ethical Issues } & 60\end{array}$

Trustworthiness and Authenticity $\quad 61$

$\begin{array}{ll}\text { Summary } & 62\end{array}$

CHAPTER IV: ANALYSIS OF DATA

$\begin{array}{ll}\text { Substitution } & 64\end{array}$ 
Augmentation

Modification

Redefinition

Other Emerging Themes

Homework

Organization

Collaboration

Communication

Inconsistencies

Issues and Improvements

102

Summary

105

CHAPTER V: CONCLUSIONS, LIMITATIONS, AND RECOMMENDATIONS

106

Restatement of the Problem

106

Research Questions and Methodology

106

Study Discussion

107

How Does a One-to-One iPad Initiative Impact Learning?

108

How Are the iPads Used in a Way that is Meaningful and Worthwhile

to Learners?

In What Ways Are the iPads Used to Engage Students' Interests?

How Are the iPads Used to Foster Communication and Collaboration?

Implication of Practice

Limitations 


\section{FIGURES}

Figure

1. The SAMR model designed by Dr. Puentedura $\quad 30$

2. The SAMR model with activities and tasks applied to those levels 32

3. Century High School ethnicity from Illinois School Report Card (2018-19) 45

4. Code colors used for themes

5. Screenshot of Ursula's notes from class 78

6. Screenshot of Rose's organization in her iPad using the note-taking app 87 


\section{CHAPTER I: INTRODUCTION TO THE STUDY}

In the early $20^{\text {th }}$ century, literacy instruction consisted of just reading and writing. In the $21^{\text {st }}$ century, literacy instruction has been broadened to include literacy that involves digital literacy from navigating search engines and websites to understanding visuals and interpreting them. Because technology has become a large part of students' everyday lives, they are required to have skills to navigate the complexity of digital devices. These advancements in devices have given educators and students the ability to transform learning experiences by creating new multimedia environments (Kellner, 2004) and giving students ways to interact with the texts and collaborate online while using the technology.

Digital literacy involves reading and writing across multiple digital media formats (Spires, Bartlett, Garry, \& Quick, 2012). It has caused educators to approach the teaching of reading differently because the digital technology requires students to have an additional set of literacy skills and strategies to help tackle complex reading in the digital age. Because online reading is complex, students need to use their inference and comprehension skills. Additionally, they need to understand how the Internet works, how to navigate searches and how websites are organized (Coiro, 2005). Teachers are preparing students in a variety of ways so that their students can access text in any form. In order for students to completely understand digital technology, teachers need to integrate a skill set of teaching students how to comprehend and navigate online reading in their specific content area (Coiro, 2005).

With the demands of higher level reading skills and advanced technological skills, students of all ages are continually using devices in the classroom. Since schools are incorporating technological devices, such as iPads and tablets directly into their classrooms, students are learning technology skills in conjunction with their customary coursework. 
Cobcroft, Towers, Smith, and Bruns (2006) found classes that combine traditional classroom instruction with information and communication technologies (ICT) have an increase in student engagement. Besides engagement, technology instruction can help students find learning in the classroom to be motivating and practical because of the first-hand or almost real-world experiences technology like the Internet can offer students in certain subject areas. To be digitally literate, the students have to be able to not only use and understand the technology, but also be able to create and produce work based on their learning with technology as well as be collaborative with partners not even in the room (Coiro, Sekeres, Castek, \& Guzniczak, 2014). In addition, the technology also offers ways to help students with disabilities interact with these real-world experiences and opportunities for research without ever leaving the classroom (Warschauer \& Tate, 2015). Through these examples, it was evident that technology offers students a variety of options for learning with or without their teachers that were not possible years ago.

\section{Overview of the Issues}

With so much emphasis placed on classroom teachers to incorporate technology, educators wonder if typical literacy lessons will be lost to the teaching of technology skills. However, the technology and literacy skills can work together in one lesson provided the lesson and the technology are used in tandem rather than in isolation. According to Coiro and Moore (2012), experienced readers use a variety of skills when they read online and offline. But, for online reading, they discovered, accomplished readers spend a considerable amount of time while reading online monitoring and evaluating the information for their suitable purpose. In addition, Lankshear and Knobel (2006) would contend that the literacy experience goes beyond 
just reading and writing. For some educators, a particular lesson can be enhanced by merging traditional literacy skills with new technology skills to accomplish the goal of a particular lesson.

According to Rowsell \& Walsh (2011), screen usage seems to rule what is known about the world, and the lessons in school need to reflect this intense change in how students are taught and how they learn. Using technology requires that an individual use literacy skills such as learning, comprehending, and interacting with the text in a meaningful way (Coiro, 2003). Carnevale et al. (2011) studied the requirements for high school students and found that students graduating from high school required advanced literacy skills which included the ability to research, gather, comprehend, evaluate and synthesize information to be successful in school and the workforce. This included using these skills in both print and non-print materials.

Nevertheless, librarians are finding that elementary level students are getting involved in digital reading programs because these programs offer more interactive experiences that include animation, brainteasers, and various appealing events that are attractive to students of the computer generation (Puente, 2012). This showed that students are getting the skills they will need for their future at an earlier age.

Besides combining technology with literacy skills, it is important to understand the new literacies required of students today. Lankshear and Knobel (2006) believe new literacies to be any way of creating, connecting, and exchanging useful information through any means of encoded texts within particular discourses. People belong to a variety of discourse communities; therefore, the meaning of any piece is open to interpretation with respect to the values and opinions they hold in relation to their culture and subject (Lankshear \& Knobel, 2006; Street, 2001). This speaks to the idea that literacy can be understood only in certain practices whether they be societal, cultural, political, or even historical practices for which they are a direct part 
(Lankshear \& Knobel, 2006). Lankshear and Knobel (2006) agree with Gee (1996) that the term "socioliteracy" refers to the more recent literacies that engage technology with traditional literacy practices.

After understanding the new literacies, educators can better understand how to teach their students with technology rather than using the devices as an added supplement to the curriculum. According to Thoermer and Williams (2012), accessing digital text by way of computer or other electronic devices can offer an engaging means that can influence students to read. Rowswell and Walsh (2011) believed that educators should teach students based on learning needs when it comes to using technology; this would help teachers address students' literacy learning by using a variety of useful technology.

One challenge, however, is to encourage cultures of learning that inspire collaborative work and understanding what learning means when it is defined by students who use the Internet to find information and learn in and out of school (Jahnke et al., 2012).

This study is designed to look at a one-to-one iPad initiative in one school through the eyes of students at the school.

\section{Research Questions}

1. How does a one-to-one iPad initiative impact learning?

2. How are the iPads used in a way that is meaningful and worthwhile to learners?

3. In what ways are the iPads used to engage students' interests?

4. How are the iPads used to foster communication and collaboration? 


\section{Definition of Terms}

One-to-one (1:1) initiative -This term is used to refer to each student having his or her own device. Although some studies may suggest one student to one computer, this study will refer to each student having a district-issued iPad (Warschauer, 2006).

\section{Description of the Study}

The purpose of this study was to explore the ways in which a one-to-one district iPad initiative impacted the high school students' learning. The study gathered information from students using the iPads to determine the iPad activities and learning experiences that they had and discover their perceptions about the use of the iPads. This exploration occurred through the eyes and voices of 12 high school students from a large north suburban high school in Illinios, and the students ranged from $9^{\text {th }}$ to $12^{\text {th }}$ grade or ages 14 to 18 years of age.

Century High School (pseudonym) had been part of a one-to-one iPad initiative in a school district of five high schools. The intent was to learn how the students in this school were using their iPads during the sixth year of an all-district one-to-one iPad initiative for their learning. An initial invitation email was sent to 400 randomly-selected emails of students at the school.

Interviews were conducted with the students to discover how and why they were using the iPads, how their use impacted their school activities and learning experiences, and what their reaction was to composing on iPads. The information from the student interviews helped to understand the student use and how they were using the devices for personal and academic activities.

In addition to the interviews, observations were conducted of the students in their classes using their iPads. Furthermore, the students provided work samples showing the activity that was 
done in the class during the observation. This was followed up with a second interview to give each student the opportunity to explain the significance of the work sample, what was being done in the class, and how they used the iPad and its functions in class. This allowed the students to explain what was happening in the class with the use of the iPad and for the researcher to gain insights into their iPad use. The follow up interview was also used to clarify what was observed during the class.

The data was compiled and analyzed for patterns and themes from the information that the students supplied during the interviews, from the actions observed during the classroom observation, and from their submissions of classwork. This helped to discover patterns among the students that could be helpful for other students, teachers, and administrators.

This study used a qualitative case study approach that, according to Cresswell (2014), was a method used to explore and understand the importance that individuals attribute to societal or human issues. A case study will produce a rich explanation of the subjects being studied (Merriam, 2009). Typically, in a case study, the researcher will develop a thorough analysis of a program, event, activity, process or individual or individuals (Creswell, 2014). This case study looked at the implementation of an iPad initiative with high school students. Since students were interviewed about their iPad use for their academic and personal activities and learning experiences, they were asked to describe how they were using the devices and the impact these devices had on their learning experiences. Their answers to the questions allowed the researcher to look for patterns and themes. A bounded system, which looked at one case with multiple sources of collected information (Merriam, 2009) was used because only high school students from 9th to 12th grade who used iPads for their learning experiences were studied. Creswell (2014) would agree that a case study would often be a thorough examination of a particular 
program like the iPad initiative in order to collect data and analyze it with a specific group of students. Using interviews, observations, and work samples, this qualitative research study explored the students' experiences with the iPad for their personal and academic use.

\section{Theoretical Perspective}

For this study, two important theoretical perspectives were used to inform the framework: the constructivist theory and the SAMR model. These theories were chosen because they help drive the understanding of learning with an iPad initiative.

According to Merriam (2009), a theoretical framework is an essential structure or outline because it will connect a variety of perceptions with accepted language with an already existing literature foundation and understanding.

The first theoretical perspective that informed this study was the constructivist theory. Constructivism is the understanding of the world through a variety of personal interactions and experiences (Piaget, 1964; Vygotsky, Hanfmann, \& Vakar, 1962). More recently, the construction of knowledge has been explained as becoming more dependent on social learning and the understanding that learning occurs between and among students (Leu, Kinzer, Coiro, \& Cammack, 2004). The social constructivist would explain that the learner plays an important role in choosing to interact or learn, in order to acquire new knowledge. This was important for this study as students were asked how they viewed their learning with the iPads, and how that learning was observed as they interacted with the devices in their classroom.

The second theoretical perspective that informed the study was the SAMR model. The SAMR model, developed by Dr. Ruben Puentedura (2006), described technology integration and use through four levels. SAMR, which stands for substitution, augmentation, modification, and redefinition, was used for the integration of technology for teaching and learning. According to 
Romrell, Kidder, and Wood (2014), the SAMR framework can assist educators in making decisions about instruction with iPads by offering activities at all levels. Furthermore, the researchers found that the levels of the model are quite subjective; however, any opportunity in which to design activities around the higher levels of the model will bring greater transformation of learning.

\section{Significance of the Study}

This study helped to describe how students' learning takes place based on an implemented one-to-one iPad initiative. With many schools incorporating or implementing more technology into the classroom, this study aimed to find out how students' learning was different when using iPads. This study emerged from the recent full implementation of a one-to-one iPad initiative into a school district. Because all of the students used school-issued iPads, the study sought to discover how students' learning took place when using a digital device. The investigation started with an inquiry into how iPads were used for learning when they were accessible to students at all times. As Lankshear and Knobel (2006) point out, students in the current generation understand digital devices and are able to multitask to include chatting or blogging as part of their learning while staying attentive to the class task.

Because students have done so much reading online and on devices, the need arose for studying how their practices have changed once they had a device available to them throughout the school day. It was important to discover what students had to say about not only the reading process but also other school-related tasks on the iPads. Results from this study provided information for teachers and administrators about the impact the digital devices had on the students and their work. 
This study filled a gap by providing the students' views of iPad use and ability to express their impact on their learning. This information can help educators and administrators make adjustments to the curriculum as it pertains to the use of iPads for any content area that requires reading, researching, and note-taking. The information can also give administrators the information necessary to design more professional development for teachers who need assistance in the area of technology implementation. In addition, the students' responses can help teachers understand the digital world that students live in and the importance of understanding technology and its part in the curriculum and the educational system. Finally, their responses can give insight to what the students themselves think about the iPads and their own learning. This may help teachers learn how to reach their students in a variety of ways. The data will help educators make more informed decisions about using the iPads for assignments and learning. Teachers and administrators need to know how students are using the iPads for their learning, and their voices will help answer some of those questions.

\section{Limitations}

As with any study, there were limitations recognized. First, the case involved 12 students from one high school from one district. These results cannot be generalized beyond this scope other than what these students at this school shared. The notes from the interviews allowed for generalizations if patterns or common issues existed, but these generalizations were limited to the information from the participants. This was an advantage as well, because there was some control over what emerged based on the interview questions, without looking for something in particular. To overcome this, pertinent questions were asked to get information about the students' iPad use and their learning when interviews were conducted and when students' were questioned about the observations and work samples. The study was trying to find out how 
students used their iPads for learning, and it was limited to the results from these students and was not able to be generalized about all high school students and their iPad use.

Another limitation was the participants themselves. As in any qualitative study, it was important to get the participants to be cooperative and give information about their experiences with the iPads. For some students, this was difficult to do with someone they did not know. Therefore, it was very important to establish a rapport with the students so they felt comfortable and at ease when they were interviewed. An appropriate amount of time was spent getting to know each student before the actual questioning began, and the students were given reassurance that their questions did not have any bearing on their grades in their classes nor would their answers be shared with anyone else. This can be a basic disadvantage of qualitative research, but it can be overcome as students get more comfortable with the interview process.

Finally, another limitation of this method would be the researcher interpretation (Fellows \& Liu, 2008). As with most qualitative research, it was important to be fair in representing the perceptions of the participants in the interpretation of their feelings and emotions. Also, in some occasions, students were asked to clarify their answers in order for the researcher to clearly represent and interpret their particular situation. This was helpful so the researcher was able to avoid drawing the wrong conclusions about an emotion or event. However, analysis of the data can be difficult because it is at the discretion of the researcher (Fellows \& Liu, 2008). It was important for the researcher to uphold the integrity of the research process and proceed to interpret the data that was present regardless of what was discovered. One way to help avoid pitfalls was to do member checking with the participants. According to Lincoln and Guba (1985), “The member check, whereby data, analytic categories, interpretations, and conclusions are tested with members of those stakeholder groups from whom the data were originally 
collected, is the most crucial technique for establishing credibility" (p. 314). A member check was performed in which the students were given copies of their transcriptions in order for them to see their own words and to see that the information that was shared in the interviews was an accurate depiction of their ideas. They had the opportunity to read over their transcriptions and clarify anything that may have been misunderstood.

\section{Overview of the Study}

This chapter introduced the purpose of this study, which was to investigate a one-to-one iPad initiative among high school students. Also, the chapter introduced an overview of the issues related to this research and included the background and significance. This chapter also provided an overview of the research questions, research methods, and definitions of terms used. Chapter 2 contains a review of the literature related to the use of technology as it relates to students' learning practices. Chapter 3 describes the qualitative methodology that was used in conducting the research. Chapter 4 is a presentation of the data and findings. Chapter 5 includes responses to the research questions based on the data analyzed and implications for future research. 


\section{CHAPTER II: REVIEW OF LITERATURE}

Technology is continually changing, which also changes the way students learn. New technology creates new learning possibilities and new challenges for both teachers and students. Students today are considered to be digital natives (Prensky, 2001) and described by Penrod (2007) as students who have grown up with technology and the ease in which they are able to adapt with the changing technology around them. Penrod (2007) would also contend that those who are older and have seen the expansion of the digital age would be considered digital immigrants. Although not all adults are digital immigrants and not all school-aged children are digital natives, it is important to understand that students are often able to adjust to technology challenges to learn more easily because of their previous experiences with digital devices, computers, and video games (Tapscott, 1998; Prensky, 2001). Gee and Levine (2009) would argue further that certain types of video games may even have a place in the classroom at some level since students can have options and control their own learning. This chapter will present the literature related to the use of iPads in a classroom environment, the implementation of digital practices, and how the use of technology compared to its printed counterparts. In addition, the research also showed how technology differed from elementary to higher education in the use and understanding.

In order to understand students' learning in a digital technology environment, it was important to understand mobile learning as learning that is instantaneous at any time in any place for students (El-Hussein \& Cronje, 2010). A debate exists as to whether or not the use of technology such as iPads or other digital devices actually produces better learning. According to Wenglinsky (1998), the drive behind the inclusion of technology in schools is to increase learning and improve academic performance and not to just provide top-of-the-line equipment. 


\section{Benefits of iPads in the Classroom}

Literacy demands on students today have gone beyond the printed text. As Joseph (2008) points out, "High school graduates are expected to read, analyze, interpret, and write about material from a variety of sources, independently processing the content and making connections between new information and existing knowledge" (p. 54). But, in order for this to be beneficial, students also need to know how to transfer that reading to navigate technology and be able to discriminate all the digital information that bombards them. Students need to learn computer skills to be able to find, assess, and utilize a variety of digital sources (Joseph, 2008).

According to Warschauer and Tate (2015), students using technology can create multimedia projects to demonstrate their understanding, and teachers can individualize, differentiate, and personalize lessons to meet their students' needs. Bebell and Kay (2010) studied eighth grade students and their use of computers and found that students who had recurrent use of their computers for leisure at home tended to have higher English-language arts achievement.

More specifically, benefits of iPad use in the classroom have been noted. Some researchers pointed out several positive results and educational benefits that included more student-centered learning and better student engagement (Cochrane \& Bateman, 2010; Dermirbilek, 2010; Wang, Shen, Novak, \& Pan, 2009). Others have stated that mobile learning has given educators and students the ability to turn any space into a learning space (Cochrane \& Bateman, 2010). Additionally, one benefit of the iPad was the opportunity for individualized instruction which allowed students to move at a speed that was personalized for them (Warschauer \& Tate, 2015). This could be especially beneficial for students with special needs or those who need extra reinforcement with a second viewing. 
For some students, technology advocates suggested that the interactive ability of the iPad creates a natural learning environment for many of today's students because they have grown up with digital devices as a common part of their lives (Prensky, 2001) while others argue that teachers cannot assume students' level of competence when it comes to computer technology (Rossing, Miller, Cecil, \& Stamper, 2012). In a Michigan school district, Zeeland Public Schools replaced textbooks with iPads for every high school student (Smith, 2011). This one-to-one initiative had teachers in the district, going paperless, but also recording entire lessons on video and making the lessons available to students. This enabled absent students, who would have otherwise lost a day of instruction, to be able to get the material that they missed (Smith, 2011).

\section{Increasing Reading Skills through Technology}

In classrooms today, literacy education is being revamped as new technology requires new skills to help support literacy (Leu et al., 2004). New literacies such as Web-quests or blog responses (Coiro, 2003; Kimmel, 2012; Penrod, 2007) require new reading and writing demands that need to be addressed in our students' classrooms. These activities require critical thinking and problem solving with a purpose that cannot be duplicated with traditional question and answer assignments (Coiro, 2003; Spires \& Estes, 2002), which includes reading skills that are required for digital reading. According to Leu (2001), there are numerous possibilities for literacy in terms of technology that were not available before that have developed in a relatively short period of time. This has caused the function of literacy to change since students are learning more in a digital format than from traditional print books. Students need more skills to function in both literacy spaces.

In order to increase the use of technology, Puentedura (2006) suggested that teachers use the SAMR model that he created for technology integration with their students. SAMR stands for 
substitution, augmentation, modification and redefinition when evaluating the level in which technology was used and integrated for teaching and learning. At the first two levels of substitution and augmentation, the use of technology is to enhance what was already being done but without paper and pencil. At the third stage of modification, learning and creating begins to be transformed. Finally, the redefinition stage is where technology allows new items to be created that would not be possible without the use of the technology.

Hamilton, Rosenberg, and Akcaoglu (2016) suggested that all levels of the SAMR model can help engage students in classroom activities depending on the age of the students and the concept being taught. With the SAMR model, that engagement is at different levels to fit the needs of the students in the class and their comfort level with technology and the tasks at hand.

Besides considering SAMR, Leu et al. (2004) assert that students also need to learn about information and communication technologies (ICT). These new literacies include not only reading on the Internet and locating information, but also learning about using search engines to locate that information. These other literacies include reading information on a website and being able to evaluate websites for usefulness based on the purpose, inserting pictures, using basic word processing features, implementing online discussions, communicating appropriately, and using inferencing skills when navigating hyperlinks (Leu, 2001; Leu et al., 2004; Sheppard, 2011). These appear to be the basic framework of necessary skills to navigate online understanding in order to be successful. By teaching these skills in conjunction with the use of technology, teachers will yield the best results from their students by helping them function in a digital environment. "Educators must continually gauge students' level of knowledge and comfort with new information and communication technologies, and they must not assume that students are prepared for new technologies" (Rossing et al., 2012, p. 17). Furthermore, using an 
iPad or any digital screen requires different processing skills that include reading hyperlinks, understanding the visuals and their aesthetics, and the animation of text as well as interactive practices of clicking, scrolling, and increasing and decreasing text structure (Hutchison, Beschorner, \& Schmidt-Crawford, 2012; Liu, 2006; van Wyk \& Louw, 2008).

Teachers, therefore, can assist with educating students with technology by incorporating a variety of online tools to help revamp traditional foundational skills and help build the skills of problem solving and critical thinking and develop media literacy (Warschauer \& Tate, 2015; Gee \& Levine, 2009). Grant et al. (2015) found that a study of iPads in K-12 classrooms revealed that students were more excited about learning when using iPads. The researchers found the devices to be motivating for students, especially those who had never used a device before. In addition, Francis (2012) found that iPads enabled students to be more engaged when they do not feel comfortable raising their hands in class. When teachers were able to use a variety of advanced organizers, students felt more compelled to participate anonymously.

\section{Teaching Reading}

According to Dale (2008), teaching reading with technology can also help students to discover new technologies and their own creativity as a learner. When students are learning to read, digital devices can easily help by using audio narration features and text highlighting (Ciampa, 2012). This allows young readers the independence to read alone while continuing to discover the enjoyment of reading. Furthermore, students can also use technology to create projects with their reading that requires them to synthesize a variety of information. Ragen (2012) inspired her students to read a book and then create a book trailer that encouraged them to be creative and thorough that goes beyond just substituting paper with technology. Her action research found that her male students enjoyed the freedom to choose, the ability to be creative, 
and the opportunity to collaborate on a worthwhile assignment with their reading. Her students also appreciated that the book reading had a purposeful assignment attached to it that enabled them to use their technology and creativity.

Teaching reading with technology is also grounded in helping to meet the needs of the gender differences. With more digital reading available, the gap between boys and girls may begin to narrow. Boys still trail girls in reading achievement, and boys don't spend as much time reading as girls do, particularly in the teenage years (Brozo, 2010; Merisuo-Storm, 2006; Smith \& Wilhelm, 2002; White, 2007). However, researchers found that the gap between the genders has been overstated in some areas, but they recognize the reading differences in the genders (Barrs, 2000; White, 2007). Brozo et al. (2014) studied the PISA of 2009 and found Ireland and Korea showed the gap is narrowing with the use of digital texts.

\section{Literacy: Digital Text Versus Traditional Text}

In order to read well using print, students need traditional skills such as comprehension, inferencing, and making judgments, but digital reading requires that students interact differently using more background knowledge, higher levels of metacognitive skills, more inferential reasoning, as well as the ability to manipulate databases and hyperlinks (Coiro, 2003; Coiro, 2005). Readers of digital text are also able to access background knowledge, get definitions to new vocabulary terms, and find related information by using the search tools (Biancarosa, 2012; Coiro, 2005). These features allow for immediate interaction with the text that a traditional print text does not offer.

For beginning readers, the digital technology has become a replacement of what has been used in the past (Kimmel, 2012; Larson, 2010). The single records with a follow-along book that would "ding" to turn the page have been replaced with digital readers with a text-to-speech 
feature. Now, as Kimmel (2012) points out the beginning readers of today are using the read aloud feature to help with reading fluency and to increase vocabulary as they follow along, just as many from previous generations did with records or CDs. These features are also important for creating a balanced approach for students with disabilities as they learn to read and write (Carnahan, Williamson, Hollingshead, \& Israel, 2012).

Research suggests that new and emerging technologies require digital literacy skills that help make students more literate. Tools such as blogging, using social networking, writing fan fiction, generating media, creating podcasts, using e-books or games, and evaluating useful websites and hyperlinks (Alvermann, Gillis, \& Phelps, 2013; Alvermann, Hutchins, \& McDevitt, 2012; Black, 2009; Coiro, 2005) are all innovative experiences that students engage in to improve their reading and writing that cannot exist with print text. These experiences have also become the focus of some students' future, and they are required skills to have in order for students to be participants in today's digital society. Black (2009) suggests that students' previous literacy education was based on literacy being academic and linear print from a book. Texts that are web-based are usually nonlinear because they are interactive in nature, and they include multimedia structures, which create new opportunities for students to turn thought into something of significance (Coiro, 2003).

In addition, Larson (2010) found that a classroom setting with digital readers and e-books opened up a variety of new literacies because of their interaction with the electronic text. Larson (2010) observed two female students using a Kindle edition of a book and found that the digital devices provided support to students and teachers, and that “... participants used new literacy skills and strategies to envision and access the potential of the digital reading device" (p. 19). For the second grade students, the researcher found them accessing the built-in dictionary, adjusting 
font sizes, and activating the text-to-speech features to help support their comprehension. These features, although elementary, can be utilized by students other than second graders to aid in reading comprehension. The text-to-speech feature can be an asset in adapting reading for students with special needs or requiring accommodations through an individualized education plan (IEP). These capabilities would not be possible with a typical print text (Carnahan et al., 2012). For Larson's (2010) subjects, the text-to-speech feature was used for difficult passages, but turned off when reading was easier.

According to Puente (2012) digital reading can create personal learning experiences for students who struggle. In particular, the digital reading helped to create more interest in nonfiction, especially for younger readers, which is a predominantly significant element of the Common Core State Standards (CCSS) initiative (Puente, 2012). With these state standards, the digital reading can help to engage proficient readers as well as assist students with learning disabilities or reading deficits. Bromley (2012) found that after reading one traditional text, students can be asked to research for more information using digital readings and then synthesize their findings. By being able to access digital information, even from their smartphones, students can open up a world of information that will meet the Common Core State Standards (CCSS) for vocabulary knowledge, comprehension, and using technology and digital media in one assignment related to a text (Bromley, 2012).

Teaching the reading process with technology also differs for students with Attention Deficit Hyperactivity Disorder (ADHD). In a study conducted by McClanahan, Williams, Kennedy, and Tate (2012), the researchers wanted to try to improve the reading of a 5th grade male student. Following other studies that suggested the use of information and communication technologies (ICTs) to increase literacy, they believed the use of an iPad helped with the boy's 
reading tutoring session assignments. The researchers found that the student was "excited to read on the iPad," and he showed "improved attitude toward his schoolwork" (p. 25). They were able to conclude that his reading ability improved because of his engagement in reading on an iPad through pre- and post- testing of his reading achievement. The student was able to access features on the iPad that aided in his comprehension, and the iPad motivated an already defeated, reluctant reader.

\section{Student Choice}

One aspect of literacy education with technology was an increase in student choice. With all of the digital technology available to students, the students have more choices in what they could read. Students have the ability to read an e-book on a tablet or iPad, or they can read an online story on their desktop or laptop computer. Because access to technology is readily available, this may increase students' choice when reading (Biancarosa, 2012; Frey, Fisher \& Lapp, 2015). Although reading instruction that is teacher-directed is important, researchers believed that it was the student reading choices that actually had the biggest impact on student reading achievement because it gave students the opportunity to search further for personal interests (Biancarosa, 2012). Students needed to be able to read something they chose whether it was a book or an article to supplement what they were studying. This increased motivation, interest, and the ability to make their own choices (Allington \& Gabriel, 2012; Kirkland, 2011).

Flowerday and Schraw (2000) found that teachers giving their students choice in general even on assignments increased students' motivation and engagement. Although there is no guarantee that students are learning, their hope was that if their students were reading, they will continue to improve their reading skills. In their study, they reported nearly $70 \%$ of teachers had mentioned that giving their students ownership was the most important consequence of choice 
(Flowerday \& Schraw, 2000). The students' choice did not stop at reading; they enjoyed having a choice for projects and homework as well. Choice may not, however, result in engagement and learning, because they found mixed results in those areas.

When students are given choice in their learning, research has shown that students are more motivated. As students learn to navigate the digital readings, they become more motivated to choose and probe on a more personal level (Biancarosa, 2012). Technological devices give students the ability to investigate their interests immediately, especially if they have a personal device with them. This mobile learning allows students to read something on a website or blog and gives them the opportunity to post comments on blogs or websites, since "students are motivated to contribute their own ideas and efforts toward these authentic issues" (Coiro, 2003, p. 460). This motivation is to not only read, but also feel compelled to reply, which seems to increase students' motivation to read text on a digital site. Therefore, the interaction of reading and responding only increases their literacy skills, particularly without judgment (Tapscott, 1998).

\section{Motivation}

In a study by Joseph (2008), motivation seemed to be a key factor affecting students' learning. She surveyed more than 600 students in six school districts and found that almost $60 \%$ of students had not completed assigned readings for class. Although there were a variety of reasons why students didn't do their assigned readings, Joseph's (2008) survey only spoke to the motivation that students lack when reading assigned readings. Student choice and technology can be used to increase the motivation for students' learning because the students found the technology more engaging (Laverick, 2014). Increased motivation and engagement were two 
conclusions she was able to draw from using technology with striving K-6 grade students in a summer reading program (Laverick, 2014).

Also at the elementary level, one school saw an increase in reading since the implementation of a digital device program called myON (Puente, 2012). The technology motivated them, and the students began reading more, with special attention given to non-fiction works. Similarly, Thoermer and Williams (2012) found that "the unique medium and scalability of digital texts offered a different literacy avenue for readers, which, in itself, can motivate students to want to read" (p. 441). Two studies found e-books to be motivating for all of their young participants (Merisuo-Storm \& Soininen, 2014; Millard, 199).

Because digital technology can accommodate any interest, the digital platform gives choices in reading that meets the students' needs and increases their motivation to read. Barrs (2000) found that the gender gap really is more about girls being more vocal. In addition, the Internet continues to encourage all youth to read in a variety of ways and be effective in promoting language and literacy skills through a variety of interactive activities (Blok, Oostdam, Otter, \& Overmaat, 2002; Castek, Bevans-Mangelson, \& Goldstone, 2006).

Also, teacher perception can influence student literacy and learning. Bozack (2011) found that teacher perceptions seemed to influence students' academic reading habits. This can be important when studying the use of technology for reading because people often assume that boys are good with video games and computers. While the students in her study characterized themselves as good readers, their teachers had different perceptions of the students' abilities. This continues to demonstrate the different perspectives students and teachers have about aptitude and reading effort. 


\section{iPad Use in Higher Education}

In a study conducted at Indiana University-Purdue University Indianapolis, Rossing et al. (2012) studied iPad use in the college classroom. Through student surveys, college students replied that they appreciated having easy access to the Internet, instant access for learning, information beyond the textbook, and the ability to easily collaborate with peers. The students in the study also frequently commented about the convenience of using the iPads for classes; however, some students felt clearer task explanations or purposes were needed to use the devices effectively. Some students reported that there was a novelty effect in using the iPad that may have increased motivation and interest but wore off over time. The students in their study enjoyed the iPad because it changed the format of class from a traditional lesson; nevertheless, the students admitted to being easily distracted by apps or spending too much time trying to figure out the device. Therefore, the researchers concluded that for some it proved disappointing and annoying rather than productive. Finally, the participants' main complaint was the reliability of connectivity when using the devices.

Sloan (2012) also found in an iPad pilot study that the class average rose slightly over the previous two semesters that the course was offered suggesting that the e-Textbook did not have a negative effect on students' grades. In addition, the college students also found that iPad use helped to promote a collaborative learning environment, and it was adaptable for their learning styles and preferences. With the higher education classes adapting to the use of technology, there seemed to be many ways that the students were using the devices to enhance their learning experiences. 


\section{High School iPad Use}

The teaching of literacy with digital technology may also be beneficial at the high school level. Welch (2010) conducted a study of ninth grade students who were placed in a reading program because they were reading at least two grades behind their peers although not formally identified as struggling readers. The study looked at the factors that promoted reading success but also those factors that had hindered adolescent struggling readers through computer technology usage as an intervention program. The computers in the class were loaded with a variety of specialized software to promote reading engagement. Student performance was evaluated using the Gates MacGinitie Reading Test, Third Edition (GMRT) in September and May. The researcher's results suggested that computers should not be used as a substitute for independent reading or comprehension lessons. However, she also found that software programs often cause students to become bored, and students needed computer features that instructed more and entertained less. She also concluded that the computer does not take away the reading struggles that students have.

In a similar study of high school students, Frey et al. (2015) found that urban high school students enjoyed the iPads and even did more of their work. Their students had improved their overall grade point averages and increased Lexile reading levels because their work was getting done. The researchers attributed this to better student engagement with the iPads and a higher interest in content when using them. The researchers also found that the teachers were able to have students work on collaborative assignments, and they were able to incorporate a blended learning style.

In a study conducted by Kalonde (2017), the researcher explored the use of iPads in a rural high school with 9-12 grade students. His students used an iPad cart, and he discovered that 
the teachers used the iPads only about $18 \%$ of the time, and students used them about $33 \%$ of the time. He concluded that just because the students had access to the technology didn't necessarily mean that they were using them in class. He also found that since students used the iPads more than their teachers, the students may be more accustomed and capable than the teachers when it comes to experimenting with new technology for school than their teachers.

In a study by Ward, Finley, Keil, and Clay (2013), the researchers found that iPad use in a high school science class was riddled with off-task behaviors until the students were given more parameters such as time limits and individual calculations. Once students were given more directions, the iPad activity and lesson were more successful, and the students were able to complete their science lab. The researchers also suggested that students collaborate on a shared document using Dropbox or Google drive when compiling their results. In addition, the researchers shared that instructors should design lessons in which students can type on a PDF, which allowed students to write on portable documents like lab reports.

Although students today have become very technology savvy, they still need to be taught the uses of a device and about Internet sites. Welch (2010) did not have students read items such as newspaper or magazine articles on the computer. Adults, including teachers, will often complain that students do not read newspapers and magazines. But, high school students in particular are getting their news by other means and almost in real time. Stassen (2010) set out to study social media usage. She discovered that many news-worthy stories were first reported on social media like Twitter or Facebook. Since many students get their news in this fashion, teachers need to consider the importance of literacy in which students are involved. They are not reading traditional newspapers because to them it is old news. They don't wait until it hits the newsstand because they are reading it as it happens from people who are there who are posting 
or tweeting about it. Educators can teach students to read more information as it becomes available, so the students can stay informed with appropriate, up-to-date information (Stassen, 2010).

In addition, the reading of social media posts is also an important skill that combines literacy and technology. In a study on using Twitter in the classroom, Dayter (2011) concluded the following:

The positive relationships between Twitter as a means of class participation and reading strategy use, coupled with the well-documented positive associations between reading strategies and learning outcomes, suggest that tweeting-while-reading is positively related to successful learning. (p. 18)

Twitter use in the classroom is becoming a new literacy that needs to be recognized since students are quite literate in the ways of social networking and are able to manage several situations (Dayter, 2011).

In a more recent study, Howard and Howard (2017) found that a one-to-one program in California was successful based on their observations of volunteer teachers who appeared to have students motivated to use the iPads. These observations discovered that students were motivated and engaged with the activities that involved using the iPads in the classroom. The researchers saw levels of collaboration, instruction, and presentation all done on the iPad with the students and the teachers. They also noted that an important obstacle was the potential for off-task behavior.

\section{Junior High Use}

At the junior high level, Coiro (2012) found that students' dispositions toward reading in general could predict their success of reading on the Internet. She reported that students with 
positive dispositions about reading generally had higher interest and success when reading on the Internet. Additionally, she found that a majority of her students surveyed admitted to believing that sometimes it was hard to find information on the Internet, and a good portion of students reported that they could easily get lost when researching on the Internet. However, a large majority of respondents believe the Internet has made learning more interesting, and they enjoyed doing research projects that involved using the Internet.

\section{Elementary Use}

Although social media may not be appropriate for all levels of students, navigating the digital literacies is one area that affects all students. Walsh et al. (2007) studied the ways students read and engaged in digital texts. Their study, although small, considered a specialized way of teaching grammar. Their findings concluded that this group of elementary-aged students were highly motivated to use technology to learn and that the students could exhibit simple navigational skills on websites. However, the students were not able to demonstrate the ability to infer, evaluate, and read critically based on their responses given. This is another area where students needed help no matter what medium they were using. The researchers also found that there may be additional research needed in order to understand clearly the kind of instruction required for the reading of digital texts. Penrod (2007) would agree that as educators and researchers try to delve further into the relationship of digital communication and education, learning about these new literacies and how they relate to student achievement becomes even more important.

On the other hand, Ciampa (2012) found that the use of e-books improved the reading motivation of beginning readers. She studied 8 first grade students who were each given a prescribed program using software for 25 minutes for 15 weeks. The method of data collection 
included observations of the students in class while they received reading instruction and observations of reading their e-book. In addition, she administered questionnaires, conducted semi-structured teacher interviews, and used reading data via the school report card. The questionnaire was an adapted version of Gambrell, Palmer, Codling, and Mazzoni’s (1996) Motivation to Read Profile. She found that students preferred the online reading format over the traditional print form. Because these participants were first graders, one notable observation was that the students, who typically misbehaved during reading time, did not have any behavior issues during the online reading time because they were engaged in the reading activity (Ciampa, 2012).

Coiro, et al. (2014) also found that an inquiry-based approach to using online information helped students learn by connecting them with real-life situations and problems. Their study looked at how $3^{\text {rd }}$ to $5^{\text {th }}$ graders interacted with a collaborative group while using the Internet to solve an assigned, realistic problem. They found that with the proper leveled steps and directions, students were able to incorporate their background knowledge of the topic, engage in knowledge of adequate technology searches using keywords, and collaborate to help each other make sense of what they were reading online.

A study conducted by Montelongo and Herter (2010) found that using technology for struggling students helped as they transitioned to reading expository text in science after reading narrative text in elementary school. The technology motivated students, which they found improved comprehension of reading science material, and demonstrated improvement in complex writing assignments. Students used modified sentence-completion tasks with contentrich paragraphs from the science textbook, which guided them to read carefully as nonessential sentences were added to help them focus on the "target" learning of the important sentences. 
Technology was also used to complete the tasks and help make the transition easier to read the difficult science texts that older students encounter.

In addition, Wright, Fugett, and Caputa (2013) conducted a study about e-book readers and their features for children and whether or not the features were being utilized to support comprehension. The methodology involved having students read a story from a traditional book, and then having them read a digital version. Participants were given certain time limits and then were given comprehension quizzes on their readings. The researchers concluded that children accessed more reading resources such as the dictionary or thesaurus when using an electronic reader than with a regular paper-based book. Their results, however, did not show an increase in reading comprehension with e-reading or digital reading as they had theorized.

Furthermore, elementary classroom observations of technology implementation can provide a wealth of data to enhance the understanding of the use in the classroom (Wetzel, Zambo, \& Ryan, 2007). At the elementary level, these researchers found that educators' use of technology differed among beginning and experienced teachers with the experienced teachers having greater productivity with students in a wide variety of technology integration.

\section{Reading Processes for Digital Reading Versus Traditional Reading}

There are a variety of differences between reading text on a digital page and reading on a traditional page. For one, the digital text or book can be interactive (Coiro, 2003). The words on the traditional page are stationary and allow no interaction other than between the reader's mind and the text. Rowsell (2014) would agree after she observed "an iPad reader touches, taps, scrolls, moves in and out of, and expands texts - touch is more invoked and dominates engagement more" (p. 122). This allows the reader to be more involved with the text. 
The use of technology for reading and learning has gone through a transformation just like other machines in society. At first a word processor just replaced the typewriter, until it had more capabilities to edit, save, and move text without erasing or losing what was already typed. Reading on digital devices has gone through the same transformation. At first, people were just reading online, but now adults and students are interacting and clicking for definitions, background information, and connections to additional activities (Johnson, 2013). Dr. Ruben R. Puentedura, Ph.D. explained the change in a four-step process of substitution, augmentation, modification, and redefinition (2006). Figure 1 shows the SAMR model as Puentedura described it.

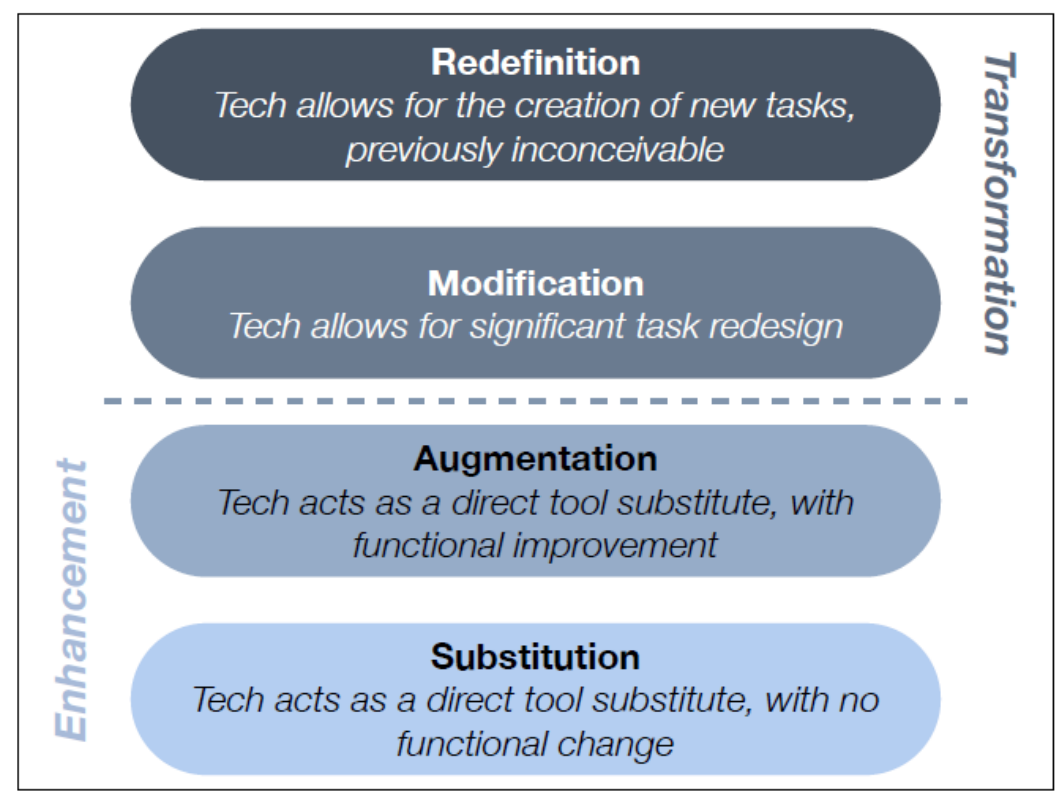

Figure 1. The SAMR model designed by Dr. Puentedura (Puentedura, 2009)

As the model shows, technology typically starts with a substitution, which is merely a new way of teaching with technology, but it doesn't transform the teaching, like using a digital 
copy of the book. But, the second step, augmentation, does not occur until the digital text is used with some sort of functional improvement. For example, using the iPad for note-taking is a substitution, but when students are able to do additional activities with their notes, they are now augmenting with the iPad. It is not until the modification stage that the technology really allows for learning to be redesigned. Here is where the students can add pictures to their notes or share them with someone else. Finally, in the redefinition stage, students are creating new tasks that were not possible without the support of technology for the activity (Puentedura, 2009), which allows students to demonstrate their learning. In this final stage, the students might interact in an online discussion to collaborate around a topic from their classroom or home, or they might create their own story to publish from their device with a story as a mentor text. Students can learn better when they are using the technology as more than a substitution, and with technology through social media, students have the opportunity to read, create, and share (Kimmel, 2012) which helps them reach that redefining stage. New learning transpires when new ways of learning happen rather than just replacing a book with an e-book.

The SAMR model was expanded by many researchers to apply to different apps and uses with the iPad. Figure 2 shows activities that students might engage in while using the iPad. Each was put into a level of the SAMR model (Created with ippaders.eu. by Schrock 2013). 


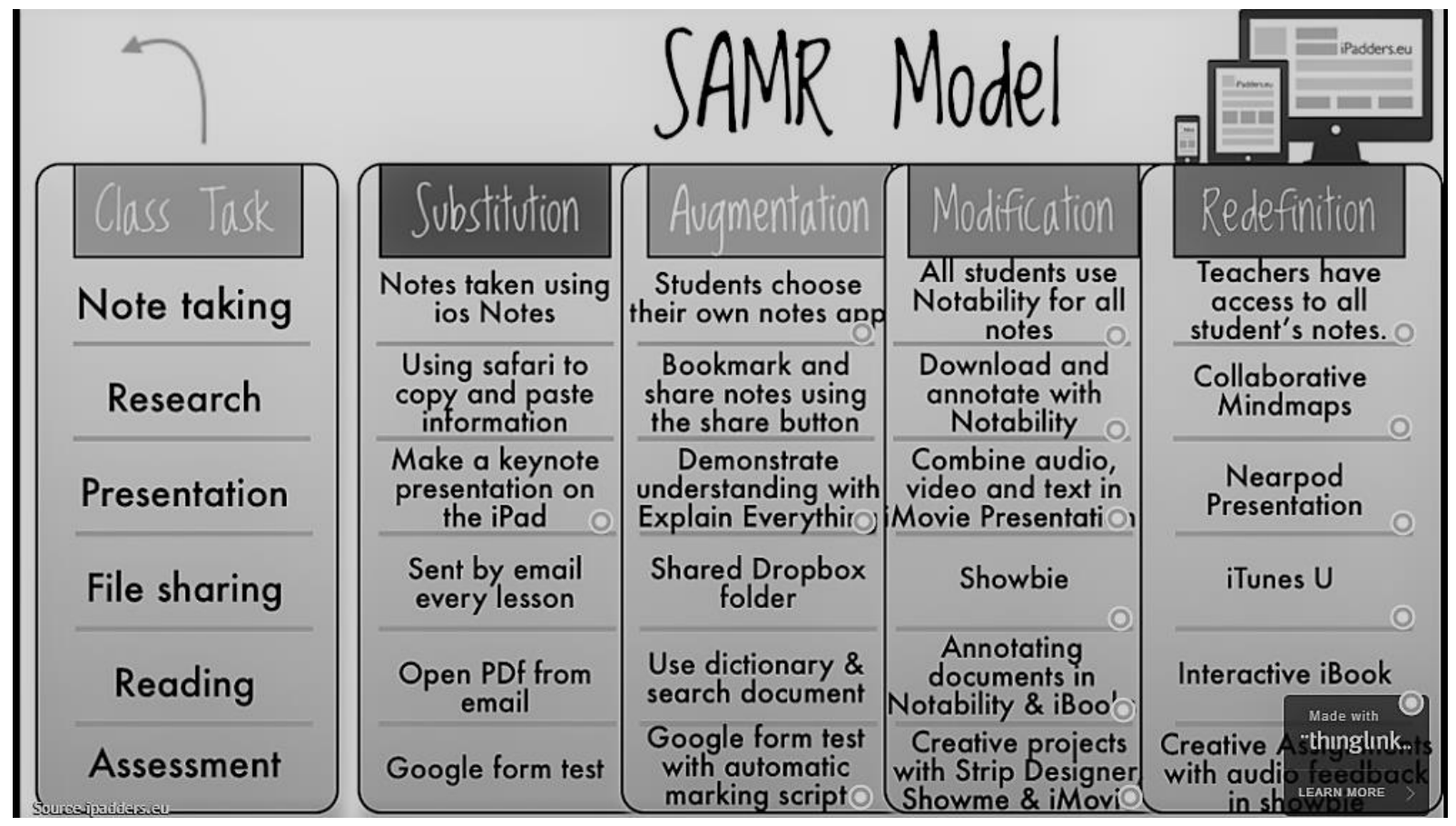

Figure 2. The SAMR model with activities and tasks applied to those levels. Created with ippaders.eu. by Schrock (2013)

Students from elementary school to high school know how to access the digital functions such as the dictionary, changing font size, using search features, and incorporating navigational tools (Biancarosa, 2012; Larson, 2010; McClanahan et al., 2012; Thoermer \& Williams, 2012; Walsh, Asha, \& Springer, 2007; Wright et al. 2013). But with digital reading, they still need to be taught "to stop, think, and make predictions about which Websites to explore" with digital technology (Coiro, 2005). Tapscott (1998) would agree when he states, “It's not just point and click. It's point, read, think, click" (p. 63). Here is where the struggle can begin to mount when students are just clicking on each hyperlink that comes before them. This creates a challenge for online digital learning.

Another process that is different between the traditional and digital genres is the ability to adjust a reading view. This can enhance a literacy experience in a digital format for students 
because they can make the font larger or change the layout from one view to another (Berkeley \& Lindstrom, 2011). This can be especially important for students who may be struggling readers or who have specific learning disabilities. These text modifications make text more accessible for students with disabilities (Berkeley \& Lindstrom, 2011). Because this makes reading easier, the hope is that they would read more.

Internet reading forces teachers to rethink how typical comprehension aspects such as finding main ideas, summarizing, inferring, and evaluating are approached (Coiro, 2003). In addition, these same comprehension skills need to be combined with new methods used on the Internet that includes hyperlinks, interactive media, electronic discussions (blogs), and synchronous information exchanges (Coiro, 2003; Penrod, 2007). The format of text on the Internet requires setting a new purpose for reading which involves a set of literacy strategies that can challenge students in a different respect than traditional text (Coiro, 2003). Students are using a higher order of thinking when they gather information from a variety of sources and synthesize that information. Those skills in reading and writing can be enhanced through the use of blog responses. These digital reading and writing exchanges cannot be replicated in a nondigital format. These blogs offer opportunities in literacy that will enable students to “demonstrate their range of intelligence beyond the usual means...." (Penrod, 2007 p. 121). This cannot be completely replicated with traditional text and paper-pencil responses.

In addition, reading on a digital device enables the reader to create new experiences. Varieties of digital reading achieve what traditional reading forms cannot, which includes the ability to hear sounds, see images, play music and games, and even have an online pen pal (Valenza \& Stephens, 2012). Traditional books cannot replicate these experiences because the reading is stagnant. For instance, author Patrick Carmen's Skeleton Creek book series connects 
junior high level students with journal format novels and web-based videos (Lamb, 2011). This transmedia storytelling requires participation that engages the reader into the story (Lamb, 2011).

For traditional text, anything from certain genres to reading levels to unfamiliar material can all create difficulties for all students when reading (Coiro, 2003). Reading text used to be as simple as just deciphering the words on a page; however, the digital landscape has created a much more interactive reading experience with embedded media clips and an increasing use of audio elements. Lamb (2011) has noted that struggling students seem to benefit from the support of the multimedia features, and students with special learning needs seem to benefit from hearing words and definitions when using the read-aloud options.

Students who use digital readings soon learn that the Internet has a "culture of interaction" that traditional texts do not have. The students who grow up using digital reading find that information is distributed to them and shared all through their own choice and power (Tapscott, 1998). Even with iPads in a classroom setting, teachers often only need to give little time for instructional use of the device before students are able to navigate the device easily independently. This appears to occur simply because students today have developed with the technology since they were infants, and they do not fear making mistakes while they navigate through their digital reading (Sheppard, 2011).

Digital reading also differs from traditional text in that the digital reading has an interactive quality that cannot be reproduced with traditional text. Students can visit websites in which they can blog about their favorite books. However, they can also engage in fan fiction, which allows the readers to alter the text, demonstrating higher order thinking and decision making skills (Black, 2009). 
But, the digital reading process differs not just for books and websites; it also differs in how students get information. Students no longer have to thumb through encyclopedias for information for school research projects. They can find the information they need at their fingertips on the Internet, provided they are given some basic strategies for evaluating websites and reputable sources (Alvermann et al., 2013). Students have even been known to "Google it" as their way of saying that they will look something up.

With school reading, students can now use applications like Gobstopper (now called Curriculet) and Subtext (now called AR360) to assist with digital reading (Hastings, 2013). For the books they assign to their students, teachers can insert leveled support using comments, hyperlinks, and questions as well as interactive discussions about part of the text (Hastings, 2013). Teachers can also add polls and quizzes, turning those assigned texts into ongoing class conversations and providing students, through Gobstopper's reporting tools, with both qualitative feedback and quantitative snapshots about individual and group progress and comprehension. The collaborative reading system allows teachers to attach Common Core State Standard skills to the assignment as well as videos, quizzes, polls, and even highlighting (Hastings, 2013). Not only can a regular text not compete with such interactive features, but also the digital text can enable the teacher to actually see a digital discussion unfolding outside of the classroom. This enables the students to interact outside of the classroom with the reading so that during the class the teacher can discuss their interactions. It is an innovative idea to teaching reading and writing. Although many wonder about the effectiveness of digital reading, one study found that similarities exist with print and digital reading. Hou, Rashid, and Lee (2017) recruited 45 undergraduate students from a communications school and assigned them to one of three reading conditions. The researchers found that there was no significant difference in comprehension 
whether reading a digital version or print version of a book. Their results concluded that the experiences were very similar when reading a paper version of a book to a digital version when it came to reading comprehension, psychological immersion, and feelings of fatigue.

Unfortunately, the digital reading can have some downsides. When reading, particularly on the Internet, students can become overwhelmed with all the media and advertisements. This bombardment of information requires that the students know how to think about the choices before them, maneuver carefully, and react appropriately to the situation at hand (Coiro, 2003). This is where appropriate teaching takes place to help guide students with those choices. Although traditional text readers are not faced with such decisions, the readers do lack the opportunity to learn to make such important decisions. This can be difficult for students with special needs if not properly trained or guided through the process of reading online.

In addition, Sheppard (2011) studied two classes of students in which one class would use iPads for reading and the other would use a traditional text. He discovered that the iPad group had a small group of students (the low group) who actually scored lower than the traditional text group in some reading comprehension categories (Sheppard, 2011). Teaching reading with digital texts can be challenging, and Sheppard's (2011) study found that students with iPads were easily distracted, which could explain their lower scores on the fourth edition of the Comprehension Progressive Achievement Tests in Reading (PAT-R) produced by the Australian Council for Educational Research. Teachers need to help students limit the distractions by giving them opportunities to use the technology for play or free time, but then also by explaining when the appropriate times are to use it for instructional purposes.

On the other hand, Ciampa (2012) contends more promising results with her study for beginning readers. She found that the use of technology, specifically online reading software, 
actually increased the reading attention, proficiency, and engagement for beginning readers, and decreased the off-task behaviors for students. McClanahan et al. (2012) had similar results finding that the technology truly helped a student with ADHD gain a full grade level in reading, where traditional reading had failed. This novelty of the digital device could be given credit for motivating him to read where the stagnant text did not work for him.

In addition, the new literacies of digital technology differ the most from traditional text for the population of students with special needs. For students with specific learning disabilities (SLD), digital technology is more flexible than traditional reading (Berkeley \& Lindstrom, 2011). Furthermore, the text-to-speech feature on many e-readers can assist students who need help with reading fluency (Berkeley \& Lindstrom, 2011; Kimmel, 2012; Lamb, 2011). This feature can also be important for English Language Learners (ELL) and students with other disabilities (Lamb, 2011).

Finally, in order for students to be prepared for college and the workplace, students need to be ready to read using information and communication technologies also known as ICTs (Leu et al., 2004). Students need help to become well versed in the skills required for new literacies (Coiro, 2003) because they are essential for the classroom disciplines and beyond formal school use. Students need to know that literacy in a technological society requires effective use of ICT's for both personal and professional lives, and for teachers, it is important to incorporate that as part of the curriculum (Leu et al., 2004).

This study contributed to the research by understanding how students were using iPads for their classroom activities and learning experiences. The study gave the students a chance to recognize the practices taking place in and out of the classroom and to voice their understanding of the impact the iPads have had on their learning. The study added to the small scholarship of 
iPad usage at the high school level and how the implementation of the iPad initiative changed their knowledge of iPad usage by explaining the activities in their classes and their learning experiences with them. 


\section{CHAPTER III: METHODOLOGY}

Students in the $21^{\text {st }}$ century have grown up using computers as part of their educational and personal lives. However, using iPads in the classroom and at home for all of their literacy needs is a relatively new phenomenon. With one-to-one programs being implemented in schools across the country at all academic levels, students have more access to personal technology than ever before. The goal of this study was to examine high school students' responses to an iPad initiative and how the initiative has created learning activities and experiences. This study allowed their voices to be heard in order for them to express their reaction to using iPads for their educational experiences. Because the iPads have been in high school classrooms, students learned to use them for their classroom activities. Since students were enrolled in one-to-one classrooms, they didn't have a choice as to whether or not they wanted to use the iPads for their learning. Since some found the devices motivating for their personal use and their academic abilities, others were using them only because the devices were issued by the school. Therefore, this study examined how the one-to-one iPad initiative impacted the students' learning experiences using a qualitative research method and more specifically, a case study approach. According to Creswell (2014), qualitative research is a method that involves trying to discover and understand the importance that people or groups of people place on certain problems or issues in an educational environment. The process involved understanding people and their experiences, and qualitative research does not look for generalities, but for specifics about people in their situation with their experiences (Creswell, 2014; Merriam, 2009).

\section{Research Questions}

The following questions were used to guide the study:

- How does a one-to-one iPad initiative impact high school students' learning? 
- How are the iPads used in a way that is meaningful and worthwhile to learners?

- In what ways are iPads used to engage student interest?

- How are iPads used to foster communication and collaboration?

\section{Research Design}

Qualitative research aims to create meaning from the world people live in and the experiences they have in the world (Merriam, 2009). This study was qualitative in nature because it took students' experiences with the iPad, both educational and personal, and created meaning from these students' interviews, observations, and artifacts. The goal was to discover how a oneto-one iPad initiative impacted students' learning activities, so a collective case study was suited for this study in order to investigate the phenomenon using various data points (Baxter \& Jack, 2008). The use of a case study approach was appropriate because it provided a comprehensive look at the implementation of the iPad for learning activities in the high school classroom. This form of data collection was best suited for a study that sought to find meaning in context from interviewing, observing, and analyzing artifacts that were at the core of this type of design (Merriam, 2009). For this study, the data was retrieved from interviewed participants, recorded field notes and data, observed participants in classroom settings, and analyzed work samples.

The qualitative research approach involved developing questions and processes, collecting data from the participants' setting, analyzing the data into general themes, and making interpretations of that data into something meaningful (Creswell, 2014). Conducting interviews was the best way for students to communicate their experiences since this allowed them to explain their experiences using the iPad that cannot be directly observed, and they provided background information that quantitative research cannot tell (Creswell, 2014; Merriam, 2009). 
This study sought to understand the use of the iPads by the students for their different learning activities. Through the interviews, observations, and work samples, information was gathered about the students' experiences with the devices, and the information was analyzed for general themes in those experiences. According to Merriam (2009), “...basic qualitative study would be interested in (1) how people interpret their experiences, (2) how they construct their worlds, and (3) what meaning they attribute to their experiences" (p. 23). Because the students were interviewed about their learning experiences using an iPad for a variety of activities, a qualitative research study produced the most desirable form of data required to find the answers to the research questions. This allowed the voices of the students to be heard and for students to convey their thoughts about their use of the iPads. Also patterns were found among the students' views, opinions, and usefulness of the iPad. Dilley (2000) stated, "Qualitative research is about finding patterns of experience in lives" (p. 2). For these students, it was about patterns from their experiences with the iPads in relation to their peers. The study looked at how the students viewed iPads in their world of learning and how they viewed the experience of using them in their classrooms and for their different learning experiences.

The study also used the lens of collective case study of a particular program, which is the iPad initiative in regard to students' learning activities. As Merriam (2009) pointed out that a collective case study requires gathering and analyzing data from several cases, and these can be distinguished from the overall case study, as in students within a school. It was also important to discover the connection of important factors that are typical of the phenomenon (Merriam, 2009). In this study, the connection was among the high school students with their iPads, and the important factors included the information about them using the iPad and the impact of the iPad 
initiative. Yin (2003) emphasizes that a case study is the preferred research method when researchers want to know the "how" and "why" of their research questions.

According to Aurini, Heath, and Howells (2016) qualitative researchers are able to scrutinize events as they happen in real time. This process involves interpreting these events from the participants' data and setting as well as analyzing that data and creating themes in order to create meaning (Creswell, 2014). The qualitative research approach is the appropriate method to focus on the students using the iPad initiative for their learning activities. Also, this approach helped to reveal their reactions to the iPad, their experiences with it, and how it helped them to engage in the activities.

Sutherland, Breen, and Lewis (2013) claimed that previous experiences as well as upcoming events may be used in such a way to make the current situation more meaningful. By combining what experiences the students have had previously with technology and iPads, it was easier to understand their experiences of where they have been and where they are going.

\section{Strengths and Limitations to Using Qualitative Method}

As with all studies, there were strengths and limitations to different research approaches. Although interviewing was considered a strength of qualitative research in general, it was particularly advantageous for this case study. It provided a comprehensive look at the students' thoughts, feelings, and opinions about using the iPads for learning. Interviewing paired with observations helped to confirm that what the participants were saying and doing were occurring when using their iPads.

Another advantage of qualitative case study in general was the powerful experiences that the students had with the iPads for interacting with digitized text. The interview notes or audio recordings were used to determine what it was like for the participants to work with the iPads for 
their classes, and get their feelings about the impact the devices had on their learning experiences. Member checks were also performed with the interviewed students, and students supplied an explanation of their work/documents as needed. This helped them convey how they felt with this iPad initiative for creating projects or completing work.

Although the case study generally offers rich experiences from the students interviewed, the process does have some limitations. One limitation was that the interview process was restricted to the information received from the students by the researcher. The information used came directly from what the students provided, even if it differed from the perspective of the researcher. Additionally the 12 students were from one high school in one district which does not allow the information to be generalized to the whole school or all high school students. Finally, the students in the study were of mixed race and gender; therefore, the results could not be applied to all students of a particular race or gender because these students were only speaking about their experiences with the iPads.

\section{Site for the Study}

For this study, the participants were high school students who were chosen from a suburban high school district outside of Chicago, and the students participated in the study during the 2018-19 school year. In order for the participants' confidentiality to be maintained, the school was given a pseudonym in order to protect those participants. At the time of the study, Century High School had a total of 2361 registered students who could have been potential research participants.

This school was part of a one-to-one iPad initiative. The district's iPad initiative started in the 2012-13 school year across the district. According to the school's technology coordinator, approximately $1500 \mathrm{iPad} 2 \mathrm{~s}$ were issued to some students across all schools in the district that 
year. Each school had approximately six to nine teachers who applied to be pilot teachers for the infancy of the one-to-one program. The following year in 2013-14, the number of teachers and students more than doubled to include approximately $7500 \mathrm{iPad} 4 \mathrm{~s}$ distributed to students in classes of approximately 30 teachers per building. The students who received the iPads were enrolled in a class that had a teacher willing to still be a pilot in the one-to-one program. At the start of the 2014-15 school year, all students and teachers were issued iPads that included the previous iPad 4s and the new iPad Airs. At the start of 2015-16 school year, the freshman class began having their iPads restricted. Prior to that school year, students did not have any restrictions and were able to access and download anything from the App Store. The seniors in the class of 2017-18 were the first students to graduate having had the iPad all four years of their high school career. With the students' iPads restricted, the district technology officials then created a self-service app system in which to push out apps to the students. Teachers were also able to request apps for class which had to be approved and then pushed to their students through the self-service app.

This high school was chosen because it was a convenience for the researcher and because of the researcher's relationship with the school. Century High School is a 9-12 grade suburban high school that had a population of 2361 students, and of those students, $26.9 \%$ are considered low income (Illinois Report Card, 2018-19). The school follows a traditional schedule of an 8period day with each class meeting for 50 minutes. It also has a college-bound curriculum that offers more than 30 advanced placement classes and more than 30 dual credit courses and boasts a 97\% graduation rate (Illinois Report Card, 2018-19).

This particular school was chosen for a variety of other reasons. After doing a pilot study at two different schools in the district, Century High School was chosen because of the ease in 
which to meet with students. When a pilot study was conducted, students were apprehensive to respond to the email invitation and few students responded. With a stronger relationship between the researcher and this individual school, it was easier to meet with students for interviews and observations.

The district, although largely white, has a variety of ethnicities based on the data from the Illinois School Report Card (2018-9). Figure 3 gives an overall view of the school and its diverse make up.

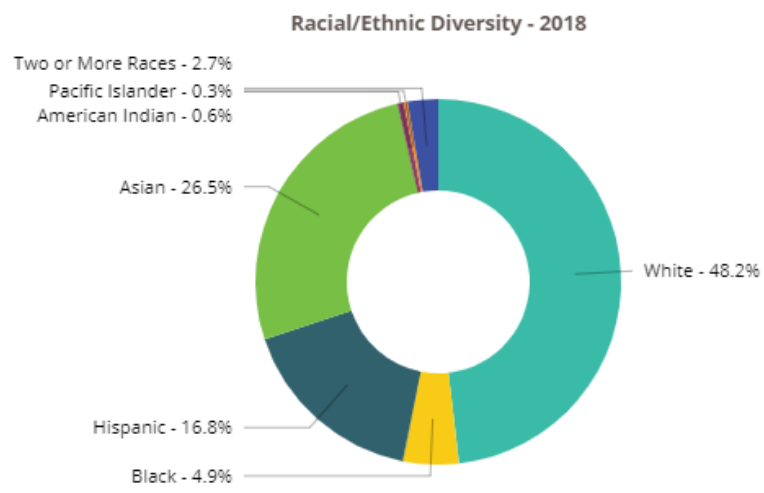

Figure 3. Century High School ethnicity from Illinois School Report Card (2018-19).

To fully understand the school and the district, the demographic information was reviewed. This district had a population of close to 12,000 students and employed nearly 800 full-time teachers. This district had an instructional spending average of over $\$ 11,000$ per pupil, which exceeded the state average by more than $\$ 3000$. The district had also been significantly above the state average for several years in college readiness based on the SAT but also the previous test ACT in both reading and math, and the school district had a 94\% graduation rate over a five year trend. 
This could be important to see if the iPads are helping students to continue on a high-achieving path or if they are an additional motivating factor.

\section{Participants of the Study}

A proposal was submitted to the Illinois State University Institutional Review Board (IRB) and was approved in order to perform the study with high school participants.

The recruitment process started with a randomly selected list of student emails that was generated by the technology coordinator at Century High School. He generated a list of emails from all students who were enrolled in the school. He then took every 10th email from the list for a total of 236 students. This list was then forwarded to the researcher as a list of potential participants so that an email could be sent inviting them to be part of the study. When this did not generate enough interest, the technology coordinator generated a second list of another 236 students by selecting every 5 th student. The researcher then sent another set of emails inviting participants to be part of the study.

The recruitment email was sent out inviting the randomly selected participants to take part in the study (see Appendix A). Attached to the email invite was the parent permission form (see Appendix B), the informed assent form (see Appendix C), and the student consent form (see Appendix D), which was for those students who were already 18 years of age. With the first recruitment email, only eight responses were returned from participants willing to be part of the study. Therefore, another recruitment email was sent out with forms, and eight more interested students responded and were recruited.

Although the study started with 16 potential participants, only 12 completed and returned all the appropriate forms, agreed to be interviewed, were observed, and submitted an artifact or work sample. A convenience sampling was used in order to have the participants available to the 
researcher during the school day. Merriam (2009) explains that a convenience sampling is used when the basis of selection of respondents is done with some convenience to the researcher in terms of time, location, and availability. The participants were current students in the school with which the researcher had a relationship. However, the participants and the researcher did not know each other prior to the study. Having a relationship with the district also allowed the researcher to narrow the possible participants since the district implemented a 100\% one-to-one iPad program in the 2014-15 school year and continued it since then.

When the students were interviewed, they were asked about their previous background and use with iPads. With this in mind, their experience would be used with their interactions with the iPads as a redefining activity or as just a substitution for an activity previously done on paper. Some students had limited experiences with previous devices while others had no experience at all. Other students had a personal iPad that they used for games. Still others expressed that they were in a one-to-one setting with Chromebooks prior to high school. This helped to relate their iPad experiences from where they came from, their iPad background, to where they were at this point in the study. According to Sutherland et al. (2013), participants' past and their future opportunities help to construct new meaning.

\section{Participant Profiles}

\section{Freshmen}

Ray was a freshman male who is of Asian/Pacific Islander descent. He enjoyed the electronics and gaming clubs as well as being part of student council. He worked with Chromebooks in junior high school and also had a personal iPad at home.

Maria was an Asian and Hispanic female student who was a freshman at Century. She was involved in medical careers club and soccer. She used Chromebooks in junior high but said 
the transition to iPad was really pretty easy because her family had a lot of technology around the house.

Ellen was a multi-racial 15-year-old freshman who enjoyed taking part in the Improvisation and Variety shows. She had Chromebook experience in junior high but no iPad experience until high school. She used the iPad now in almost all of her classes except gym.

\section{Sophomores}

Adam was an African-American sophomore male who enjoyed coding club, electronics club, and technology club. He had some prior experience with Chromebooks before high school in junior high but no iPad experience other than his freshman year.

Rose was an Asian/Pacific Islander female who was a sophomore at Century High School. She was involved in clubs at the school including swim team. She also was on the local student library board and tutored at a local center. She used a Chromebook in junior high school.

Victoria was a sophomore Caucasian female. She was involved in the school's Writer's Club as well as color guard and student council. She also had experience with Chromebooks from her junior high, but no iPad experience until she came to high school.

Cassie was a 15-year-old Caucasian sophomore who enjoyed playing golf, being on the poms squad, and playing softball for her school. In her free time she liked to hang out with family and friends. She had some experience with Chromebooks in junior high.

Ursula was a 15-year-old Asian/Pacific Islander female who was part of the school's newspaper and Science Olympiad. She moved to the suburbs from New Jersey when she was in 4th grade. She had experience with Chromebooks in junior high. 


\section{Juniors}

Katrina was a Hispanic junior female who grew up playing soccer and swimming. Now she was busy focusing on her AP classes and jazz band. She had a little experience with Chromebooks in junior high but attended a school in a different suburb than most of her peers.

Joseph was 16-year-old Hispanic male who enjoyed being part of the gaming and robotics club at school. In his free time, he liked to hang out with his friends. He had some experience using iPads on a cart in junior high that the teacher brought to class.

\section{Seniors}

Steven was an 18-year-old senior Caucasian male who loved wrestling. He had no iPad or Chromebook experience prior to high school, but now used the iPad all the time. He was a very good student who was in the midst of choosing his college for next year.

Ben was a 17-year-old Asian/Pacific Islander senior at Century High School who spent 3 years on the soccer team but mostly enjoyed being part of the Science Olympiad and math team. He had no Chromebook or iPad experience before high school because his junior high got Chromebooks right after he graduated. He recently joined the CompSci Kids coding program to teach younger students about coding.

\section{Data Collection}

\section{Interviews}

Once the proper forms were returned, the students were sent emails to arrange interviews. The interview sessions were also audio recorded, and students confirmed their agreement to the taping of the interview by signing the informed assent. Since all students submitted their forms electronically, they had their own copies of their signed consent forms for future reference 
should they need it or the ability to reach me, the chief investigator, or the university at any time during the study.

In order to collect the data, each of the 12 students was interviewed individually for 3040 minutes using a semi-structured interview format. According to Merriam (2009), a semistructured interview allows for questions to be used openly and not rigidly, and the interview is guided by the question list but allows other topics to be explored during the interview. For this research study, interview questions were prepared ahead of time (see Appendix E). Using a semistructured format allowed the flexibility to deviate from the questions depending on each participant's response, which allowed for a more authentic conversation between the participant and the researcher. As Merriam (2009) states the semi-structured format gives the researcher the opportunity to respond to the participant and allows new impressions to emerge about the topic. Each interview was audio recorded to assist with accuracy and authenticity and lasted approximately 30 to 40 minutes in length. Field notes and coding were also included in the data. These audio recordings were crucial in helping to dissect the information from each interview. This interview structure was used because it allowed for some structure with predetermined interview questions but also the latitude and flexibility to use unplanned questions based on the participants' responses. In addition, “yes/no" questions were avoided whenever possible as they did not elicit any valuable research information, and the goal was simply to get the participants to talk and elaborate whenever possible (Dana, Dana, Kelsay, Thomas, \& Tippins, 1992). Dilley (2000) also suggests conducting interviews with open-ended questions, having the intention of creating a dialogue or conversation and giving the participants the opportunity to answer, as well as helping the participant feel comfortable during the interview. 
To help facilitate these conversations, Lincoln and Guba (1986) stress the importance for the researcher to establish a good relationship with the participants so that they have a mutual understanding and a shared learning that is equally balanced. Therefore, the interviews were begun by building rapport and getting to know the participants by asking them questions that were unrelated to the study about themselves and school in general. This helped the students feel comfortable by creating a dialogue that should have put them at ease. According to Dana et al. (1992), an interview's purpose is to get the participant to respond and converse as much as possible, avoiding the simple yes/no answers. The purpose of interviewing was to obtain information that could not be directly observed about the students and their activities with the iPad. "Interviewing is necessary when we cannot observe behavior, feelings, or how people interpret the world around them" (Merriam, 2009, p. 88). The study was striving to discover how the use of the iPad has impacted their learning. This included getting their thoughts and feelings about the use of the devices and trying to find out how they viewed the impact of their learning. These interviews were then transcribed word-for-word by the researcher in order to review the participants' answers. The word-for-word transcription aided in looking for patterns in responses among the study's participants. They were then printed out and coded according to the research questions.

During the interviews, notes were taken and interviews were audio recorded with the students in the study. This helped to be as accurate as possible about including and incorporating their ideas about their interactions with the iPads. The interview process was needed when the researcher was not able to observe emotions about what was occurring in certain situations (Merriam, 2009). These emotions were also preserved with audio recording since their emphasis or inflection helped to understand the emotion behind an answer or statement. The interviews 
were in-depth in order to understand the participants' thoughts, feelings, and reactions to the use of the iPad and the questions asked about it.

\section{Observations and Documentations}

Besides interviews, all 12 students were observed. The students were asked at their initial interview about being observed. Students agreed and sent me dates and times via email that worked for the observation. The observation was scheduled and contact was made with the classroom teacher to set the day and time so the observation would be the least intrusive to the class but the most helpful as far as viewing the iPads in use.

The observations proved to be important in order to see the students using the iPad in a class, and to observe that the use of the iPad was consistent with the information shared during the interview. The researcher took notes while observing the student, the class, and the teacher. Notes were taken on what the class was doing with the iPad for the class, and then observations were made about how the study participant was interacting with the iPad as part of the lesson.

The participants were also interviewed in a follow-up interview to discuss the observation and share a copy or screenshot of what they worked on during the observed lesson. The students were also asked to give a brief explanation of the artifact that they shared. The students explained other ways the iPad was used in the class or other lessons that used the iPad for that class. The students also told shared how they felt doing the lesson on the iPad. The follow-up was rather informal and only lasted about 15-20 minutes. The follow-up interview was usually scheduled for the day after the observation if possible; however, in some instances the follow-up was scheduled for up to a week after the observation to accommodate the students' schedules. The students were questioned about the assignment or lesson notes, and they discussed what was done and how easy or hard it was on the iPad. This follow-up interview helped to corroborate 
what was observed in class with what they produced on the iPad. Students were also able to correct any misunderstandings the researcher may have had from the observations. For instance, it was assumed one student was just correcting her work, but in reality she explained that she was writing down the correct answers so she knew the answers in order to study for the test.

\section{Data Analysis}

After the students were interviewed about their experiences using the iPads for academic and personal use, they were asked about a class in which to observe. Students were observed in a class that used the iPads that was convenient for the student and the researcher. Once the interviews and observations were completed, students were re-interviewed, and students were asked for a work sample or artifact. The interviews were transcribed by the researcher word-forword. Then the transcriptions were coded and analyzed for recurring themes and patterns using manual coding. After digital transcripts were read, a list was made of recurring words or phrases. From there, digital versions of all the data samples were highlighted with those ideas where students mentioned activities that students engaged in that related to an app or category.

Also, the activities that the students engaged in with the iPads were categorized based on the level of the SAMR model. The SAMR model was expanded (see Figure 2) to include different apps and uses for classroom activities (Schrock, 2013). This expanded model was used as a guide in the analysis when rating the students' activities at the different levels. Although this expanded model was not a complete list of every classroom activity, the level most closely related in complexity and similarity as the sample was used when labeling the students' activities to the appropriate SAMR category. Each of these categories was used to determine the function and use of the iPads by the high school students. Each of the codes was given a color. From 
there, a second reading revealed different apps, activities, and uses that were also coded with highlights of other colors.

These student interviews were recorded for authenticity in order to capture the students' intonation and emotion as well as the ability to transcribe their words as accurately as possible. After each interview, the audio recordings of the interviews were transcribed and organized with a small blank margin on the right side. This allowed comments or notes to be added that came out during the subsequent readings or during the analysis phase of the procedure. In order to manage all of the data for each student, a file was created for each student on a secure computer, and a hard copy was printed and put in a binder that was organized by student and year in school. This allowed for quick reference when meeting with the student. The binder also contained a copy of each student's schedule and summary page that gave quick access to their year in school and email address as well as a picture. This helped to organize the data and keep a visual of the student when analyzing and writing about each participant.

The observation notes were transcribed and also added to the file on a secure computer, as well as a printed copy for the binder. When follow-up interviews were conducted, the printed handout with the student served as a reference for asking questions. During the follow-up interview, notes were taken that were also transcribed and added to the computer files, and printouts were added to the binder.

Finally, the students also submitted a copy of the work that was produced during the observed class. The students emailed this work sample, and it was added to the computer file for each student and a copy added to the binder. The printed copy was important so notes could be added as the students shared or showed something interesting. Each potential category or theme was given a highlight color. When a student response related to an existing theme, it was 
highlighted with the corresponding color. With electronic versions of the data, a search could be performed using a keyword or phrase that allowed the topic or themes to be highlighted. With the artifacts, work sample were compared to what was observed in the class and what was produced. Each student was asked about the work that was related to the observation. The students explained a variety of applications that they used in class. These were apps that they engaged with for class as directed by the teacher, or apps that they chose to use because they were available to them. This allowed codes to be used with the artifacts and follow-up interview transcriptions. Below Figure 4 shows a list of the initial codes and their highlight colors.

\begin{tabular}{|l|l|}
\hline Code & Category or theme \\
\hline Yellow & organization \\
\hline Bright Green & convenience \\
\hline Light blue & homework \\
\hline Purple & engagement \\
\hline Blue & interests \\
\hline Red & create \\
\hline Red font & discussion \\
\hline
\end{tabular}

Figure 4. Code colors used for themes

Finally, activities were coded that pertained to the level of the SAMR model (Puentedura, 2009). Data was coded during a subsequent reading of all the pieces of data and decision were made as to how the pieces of data really fit into one of the four levels of the model. All of the 
activities from the digital files were coded as either substitution, augmentation, modification, or redefinition, which are the SAMR levels of technology integration for iPad use.

In order to assist with the data management, a chart was created with potential students and the steps completed in the interview and observation phases. When steps were finished, it was checked off as a reminder that the piece of data or procedure was completed. This helped to insure that all steps were completed with each participant and that each participant was treated equally with respect to data collection. All students had the same number of pieces of data that could be used for the analysis, and all students were observed to add more weight to the varied participants and their points of view about the use of iPads.

The work samples were then compared to what was observed in class. During the followup interview conducted with each participant, the observation and work sample or artifact were discussed as they related to what was seen during the class. Students could clarify what they were doing with an explanation so no assumptions were made. Students may have been asked questions such as, did you ever think to take a picture of the notes? Or do you write down all of the notes word-for-word or just summarize? Their answers were coded by highlighting them with a corresponding color that was assigned to the emerging categories and themes. This allowed for all similar color-coded answers for the category or theme to be put together. During an additional phase of coding, the level of integration of the technology was applied using the SAMR model code words.

Qualitative data analysis can be a difficult procedure when looking at interviews, observations, field notes from observations, and student artifacts. According to Merriam (2009), analyzing data means looking closely and making inferences among the tangible and intangible items through depiction and explanation. In order to understand the data collected, students' 
answers were coded using the research questions and organizing the answers into categories. Caudle (2004) says, "Codes or categories are simply labels that assign meaning or themes to the evaluation data" (p. 422). In this study, the data was classified as the preliminary step before interpreting (Saldana, 2009). During the first cycle through, the color codes were used, and the uses of the iPad were highlighted as the students mentioned them. On the second time through, Saldana (2009) suggests rearranging and looking for other codes or even subcodes that start to create categories. As Caudle (2004) points out, coding helps to break down the information gathered into groups that may relate to particular events, relationships, or processes. This breakdown helped to identify the common recurring themes and patterns from the interviews (Caudle, 2004; Saldana, 2009). In addition, by allocating codes to data retrieved from the interviews, observations, and documents, a researcher can begin to build categories and then the patterns of similarities and differences begin to emerge as well as themes and concepts among the participants (Merriam, 2009; Saldana, 2009). Strauss and Corbin (1998) believe in labeling the phenomena or conceptualizing it when they stated, "We compare incident with incident as we go along so that similar phenomena can be given the same name" (p. 63). The student data was looked at for similar incidents with the phenomena of using iPads for their learning. From there the participants were compared to see if they had commonalities with their views and uses of the iPad in their classes.

Coding was started by putting all of the student interviews, observations, and documents together for each student. The transcriptions were created using a two-column system with the transcriptions on the left and the right hand margin blank for coding and notes (Saldana, 2009; Strauss \& Corbin, 1998). Saldana (2009) then suggests using a pre-coding technique of highlighting or underlining any important pieces of data that stand out or are of particular 
significance. This allowed a review for further codes, which lead into categories of organization and convenience as some very basic themes.

During the first reading of the transcript, each interview was broken down further by adding more categories to include apps that were recurring such as a note-taking app, an LMS, and Google apps like slides and docs. The students' answers were highlighted that were similar from one transcript to the next in the same color highlighter. Their comments were organized as they included patterns such as collaboration, opinions, experiences, and meaningful as it pertained to their comments about using the iPad and how they felt about that use.

Several readings of the transcript were conducted looking for recurring ideas. During the second cycle, the most obvious answers were highlighted where the students answered very similarly. As Saldana (2009) points out, it may require three to four cycles before some of the concepts become apparent. By doing this for each interview question, the patterns began to emerge among the primary and secondary research questions which included addressing the students' collaboration and communication as well as the SAMR levels of implementation.

Data was collected that had similar answers or comments that were related from student to student. The students' examples were reviewed and then if they explained the same or similar experiences or apps used, those items were coded and highlighted in the same color.

Following the suggestions of Strauss and Corbin (1998), a coding system of plus signs and minus signs was used when the first read of the transcriptions was performed. For example, all the transcripts were put together, and they were reviewed to see how the students were using the iPads. When the students mentioned a positive way in which they were using their iPads, a plus sign was placed as the code. Additionally, a plus sign was used for any literacy strategy that they mentioned that they used for the iPad, or a plus sign was placed next to information that 
indicated positive statements about the use of the iPad. Similarly, any negative statements about the iPad were coded with the word "negative" in the margin of the transcript. For example, Joseph commented, "The iPads are restricted so we can't... search whatever we want necessarily."

Next, categories were used based on the research questions. According to Strauss and Corbin (1998), categories have the power to bring life to the abstract ideas and then enable the researcher to broaden out into groups of other concepts and subcategories. Different topics or possible themes were highlighted in different colors, which allowed for each topic to emerge when repeated. For instance each time a student mentioned something about organization, it was highlighted in yellow. If they mentioned "convenience" about using the iPad, it was highlighted in green. Homework was highlighted in light blue, and "personal interests" were highlighted in darker blue. When the students mentioned ways in which they communicated, it was highlighted in teal, and if they mentioned collaborating or working together with others, those instances were highlighted in gray. According to Marshall and Rossman (1989), observation is the organized explanation of what is happening, the actions, and the work sample in the situation for the study. As with all research, the research questions remained at the center of this study, and they needed to be referred to as the data was analyzed. This helped to keep the research focused. As Caudle (2004) suggests, “...to ensure good data targeting is to keep the evaluation purpose and research questions close at hand as data collection instruments are designed" (p. 418). By revisiting the research questions consistently, the data collected was relevant and the analysis was purposeful in addressing those questions (Caudle, 2004). 


\section{Role of the Researcher and Positionality}

During this study, the researcher worked in the district as an iPad one-to-one instructor. This involvement included teaching with the iPads which had intrigued the researcher to consider what the experience was like from a student's perspective. Because the researcher was familiar with the terminology that students used when they referred to applications and particular iPad procedures used in class, it was easier for the researcher to understand what the students were explaining. Furthermore, this background knowledge of the iPad helped the researcher better understand how the students were using them and understood when the students referred to apps or websites used in this school setting.

Besides being a teacher in the district, the researcher was also a parent whose students attended one of the schools in the district. This gave the researcher a unique perspective of the technology being used by her own children as well as students in her own classroom and her colleagues' classrooms.

Because the researcher was a one-to-one teacher, she supported the use of the iPads for learning. Therefore it should be noted that she was a proponent of the iPad for leaning and used it to enhance learning in her own classroom. This could be a potential bias in the study because the researcher has an understanding of the iPad and a desire to use the iPad in a productive way. All findings were included in the results, even those that did not show the positive side of the one-to-one initiative from the students' perspective.

\section{Ethical Issues}

With any research, there are always ethical considerations for a study. "In qualitative studies, ethical dilemmas are likely to emerge with regard to the collection of data and in the dissemination of findings" (Merriam, 2009, p. 230). First, there was no relationship between the 
researcher and the students interviewed. Since the researcher has a relationship with the district, there was knowledge of the district, the iPad one-to-one program, and the district's structure. However, students were chosen who were not affiliated with the researcher. This echoed Merriam's (2009) stance when she stated: “Ethical considerations regarding the researcher's relationship to participants are becoming a major source of discussion and debate in qualitative research, especially with the growing interest in critical, participatory, feminist, and postmodern research" (p. 230). Therefore, there was minimal chance that the students' responses were trying to please the researcher, and the questions were more likely to elicit candid responses from the participants.

In addition, the research results were not purposefully excluding any contradictory information. In order to be completely ethical, data was reported that showed patterns to answer the research and interview questions. Merriam (2009) pointed out that there were opportunities in which a researcher could exclude data which may be contradictory to the researcher's views, but all data was reported regardless of the contradiction.

\section{Trustworthiness and Authenticity}

According to Lincoln and Guba (1986), the relationship between the researcher and the participant is one of mutual understanding and respect and must be established. A comfortable environment was established for the participants to be able to talk freely. This included reminding the participants that their information remained confidential and anything that they shared would not be used in any way except for the purpose of the study. They were reassured that their answers would have no bearing on their grades or their status at school.

Next, all participants were treated fairly with respect to the data received. "Fairness may be defined as a balanced view that presents all constructions and the values that undergird them" 
(Lincoln \& Guba, 1986, p. 655). In this research study, a conscious effort was made to be fair to the data as possible. This was done by finding similarities among the interviews before drawing any conclusions and evaluating the transcripts thoroughly and efficiently. With this in mind, generalizations could not be made about all students and their learning experiences with the iPads based on the interviews conducted or the responses generated from these participants. In addition, the most reliable data came from the audio recordings. The participants' words were transcribed word-for-word, and member checks were conducted as needed to assure the accuracy of the participants' data. These were conducted to ensure that an understanding was accurate, and themes and patterns were discovered. In order to do this, students were asked to clarify a point in person if possible; otherwise, they were emailed with questions to get a better explanation of what they meant by a particular response. By member checking, valid confirmation was obtained from the participant about interpreting and understanding their words during the interviews and helping to triangulate the data. A member check was also performed for the data at the follow-up interview after the observation in order to check with the students about what was interpreted. In some cases, students were able to correct mistakes that were made in the interpretation.

\section{Summary}

This qualitative research approach generated data via participant interviews of freshman through senior high school students using a semi-structured interview approach and observations. The students' responses were audio recorded for accuracy and then transcribed immediately. The interview answers were then compared, coded, and analyzed for themes and patterns. The participants were also observed and re-interviewed about the observation. During the second interview an artifact or work sample was collected. This allowed for patterns to emerge naturally in order to maintain authenticity. 
The study was significant because it allowed the students to express how the district oneto-one iPad initiative impacted their learning activities. They shared their experiences with the devices and gave insight about how technology impacted their overall experiences. With technology constantly at the forefront of education, it was important to get the experiences from the students' perspectives about their use of digital devices. 


\section{CHAPTER IV: ANALYSIS OF DATA}

Since more and more schools are incorporating technology into their classrooms, it is important to understand the impact of technology on learning activities and student learning experiences. Because many forms of technology have become so important in society today, it is no surprise that digital devices have become important in students' lives and in their classrooms as well. This study sought to discover just how students use technology, specifically districtissued iPads, and how their use impacts their learning activities and experiences.

This chapter provides the themes that emerged from the data collected. Some of the themes that emerged were part of a model developed by Ruben Puentedura (2009) that included levels of technology integration. Along with those themes, applications (apps) that the students used that helped them to work on the iPads are also explained. Finally, additional themes are explained that pertain to other ways the students used the devices for different classes and personal use.

Using the SAMR model as a guide, the data from the 12 participants was coded into the four major themes of substitution, augmentation, modification, and redefinition. There were not any significant differences when comparing the different grade levels regarding responses other than the freshmen required instruction to use the apps that they considered new, but the upperclassmen usually knew how to use the apps or could adapt quickly because of their previous years of experience with the devices.

\section{Substitution}

The first theme from the SAMR model that was evident from the data was substitution. In the substitution level, technology or a digital device acted as a direct substitute for a nontechnology activity like paper and pencil. When interviewing the students, they commented that 
they preferred having the iPad for books instead of textbooks. Even at the lowest level, the students in the study expressed that they were engaging in the learning activities in their classes simply because they could substitute the heavy books for a digital version on the iPad.

In order to help students with the digital material at the substitution level, the school district provided two important applications. These applications included Schoology, a Learning Management System (LMS) app that was provided for every student. This LMS allowed for students to submit assignments electronically and receive feedback and graded assignments back from the teachers. The other app, Notability, was the note-taking app, which allowed forms and worksheets to be filled out once pulled from other systems, like the LMS. One freshman student Maria had been taught where to go to find an assignment within a class page on the LMS, how to pull it from the page, how to use the note-taking app to complete the assignment, and then how to submit the assignment back through the LMS to an assignment folder. This retrieval of the assignment from the LMS was a simple substitution for the teacher passing out the assignment. When the students submitted it via the LMS, it was a digital substitution for handing it in to the teacher. Nothing has academically was changed, but the format in which to complete it had changed.

Sophomore Adam also commented on the use of the iPad at the very basic level. I used to have so many textbooks in junior high because especially if you are in higher classes, you have a textbook for every class that it breaks your back. So having the iPad, it's nice, and if everything is on there, I can just take my iPad and go and I'm good. I don't need anything.

This convenience was a recurring idea from many of the participants because they liked that all of their school items were contained on one device. They expressed that the convenience 
of having their textbooks and novels all on the iPad was very convenient because everything was with them always. This substitution of having all of their texts and novels in one place on this platform also helped when doing homework or studying.

Freshman Ray commented that his teachers also employed the substitution with the iPad for note-taking. "We use [the note-taking app] a lot. It's easier to write because you can type it or write it... all your notes. Like in my Spanish class, we use it for all of our practice worksheets." This practice of filling out worksheets on the iPad was a recurring idea among the participants and provided another example of substitution. Although the engagement level was low on the SAMR hierarchy, it was still appropriate for certain learning activities.

Ray also commented about the use of the iPad and its convenience. His example explained the substitution of having his materials on paper to now having them on the iPad. I use [the LMS] which is like Google classroom also, and I go on Safari a lot but for personal searches. It is really convenient. It is pretty nice because sometimes when you are writing your notes, and you're taking your notes, you could take a picture if there is a graph or something. It's so much easier. Some classes you don't have enough time to draw all the pictures out or all the diagrams or charts or graphs, so you can just take a picture and write little notes on it or type the stuff and notes that I need to get. It saves time too.

Without realizing it, Ray's comments suggested that he enjoyed the iPad for the convenience that he can substitute paper and pencil activities for simplified ones on the iPad.

Victoria also commented about the use of the iPad for convenience. "When I got to high school and I saw the iPad I thought 'Thank God!' because it was so tiny, and I can fit it in my backpack [and it] is light now and I don't really have anything else." Victoria's substitution of 
the iPad for all of her other supplies was a convenience she liked because she had less to carry in her bag. She liked the size of the iPad, too, because it made her backpack lighter to carry around.

Junior Katrina also liked the iPad for the convenience for tasks that might otherwise take place with paper and pencil. Besides using the note-taking app for handouts and worksheets, she liked that she has less paper and fewer books to carry around. She stated, "I feel like the iPad conserves a lot of space in your backpack, so it's easy to just put it in there and it's done." She also commented that she likes all of her notes in one place, and she doesn't have several notebooks or binders to worry about. "Last year I had to go buy a binder and a hole puncher too because I don't like having all of my papers loosely in there because I organize my binders too. And I feel like the paper is such a hassle." Although this is at the substitution level, organization with the iPad is important so a student can have all of her materials in one place. She added, "I have created this agenda in [the note-taking app] to keep everything straight." Katrina shows the researcher her iPad. "I will go down in every single class and every single unit, and I will go down and put everything that I need." For Katrina, the ability to organize and use the iPad like a digital calendar or planner helps her with her schoolwork and assignments.

Another student, Cassie, commented about the convenience of the note-taking app for writing.

[It's easier] because with pencil and paper, there's more work to write it out and things get like crammed in but with [the note-taking app] I can write it, and I can be like 'oh I need more space' I just shrink it and add more notes and I can highlight things easier. So I don't have to bring a whole pencil case with a bunch of stuff. So it's like more efficient and quick, like if there's a lecture I can quickly jot down notes or even type them really fast. So it's easier to use than pencil and paper. 
For Cassie, she substituted the iPad for paper and pens or pencils. She commented that using the iPad is convenient because it allows her fewer supplies. She also liked the convenience of manipulating the notes based on her note-taking needs.

For Ursula, the substitution of the iPad was also noted.

I think the iPad makes it a lot more convenient to do everything. Like everything is in one place and you don't have to ...like with poster board you would have to print the pictures out, you have to glue them...on the iPad is much easier.

Ursula's comment summed up the idea of convenience where she has everything in one place for school by substituting posters and pictures for something she can use on the iPad. There was no functional change in using the iPad to do some of her activities, but she liked the convenience of being able to substitute the iPad for simple things that she would have used before she had it. Joseph felt the iPad was convenient for a different reason.

I like it [the iPad]. It's really convenient. Especially, if kids are sick. Like what if we are going over peer editing in class and you're sick you can just... it's all on there in [the LMS]...your updates for the day, and you can just share your document with another student and do the same thing you are doing in class. It's definitely productive. And if you don't understand a homework assignment, go onto [the LMS], look up the notes, and then you've got the lesson learned for the day. It's so easy.

Joseph liked having access to all of his school materials, especially if he is sick. This substitution enabled him to stay involved with his schoolwork while he was at home recovering. He felt the convenience of using the device helped him in school.

Furthermore, Maria commented about her use of the iPad and all the things she can do with it. 
You can go on YouTube on our tablets which is a surprising feature, and there is often a news app on there, and you can read all these news articles that other people write. You can comment on other people's articles and then share your opinion like what's your point of view or what's your involvement in it. I like using it [iPad] for math because there is a calculator on there and I can just use the split screen, and I can write it down, zoom in, and write it down. Whereas if I did it on paper, it's not organized or accurate. This was also apparent when Maria was observed in class. She was using her iPad and a calculator, but she then was also demonstrating the use of the split screen like some of her peers. Ellen also commented on the use of the split screen. "It's awesome because you can have two things open at once so I can look at the answer key while I'm looking at my work. Checking my work and stuff." She liked being able to check here answers with two different applications open.

For freshman Ellen, she demonstrated using the iPad for a substitution in her math class. She said she liked her notes "all in one place" like a notebook, but she felt it was "easier to erase stuff when you make mistakes because I tend to make a lot of mistakes, so erasing it messes up the paper, but I can click 'undo' [on the iPad] and it's good."

Using an LMS enabled students and teachers to connect to each other and the curriculum through digital assignments. Maria demonstrated the convenience of the substitution of the iPad when she was being observed in her math class. "We retrieve the notes from [the LMS] and push it to [the note-taking app] each day," Maria explained during the initial interview. During the observation of Maria in her algebra class, she pulled up her homework, which was a completed worksheet on the iPad. She was also seen correcting her homework when the teacher went over it, and she changed the answers she had wrong. "I like changing it and having the right answer so when I go back to study, I study it correctly and can practice to get that correct answer. Helps me 
get it right next time," she explained during the follow-up interview. She also completed the practice problems in the note-taking app as she followed the teacher, who was writing on his iPad and projecting it on the overhead for the class to see during the lesson.

Although this observation did not demonstrate a high-level interaction with the iPad, it showed a substitution of the iPad for paper and pencil to take notes. Students, including Maria, were engaged in taking their notes, but they were also able to adjust them as they needed. However, Maria and other students commented that they preferred to take notes on the iPad because they can easily make changes, as she demonstrated.

Rose's comments were similar to other students' statements about using the iPad for notes. "[Our math teacher] gives us a choice. She does it on her iPad, and she pushes out notes once and a while. If we really wanted, we could copy it down in our notebook, but it's just easier on the iPad just to fill in the blanks." Rose liked that she has a choice to use the iPad or paper, whatever was most convenient for her. She chose to substitute the iPad for the paper and pen because she liked being able to replicate the teacher's work electronically. This choice made her take control of her own learning by choosing how to take the information presented in a way that would be best for her. It was a simple substitution of paper worksheets with worksheets on the iPad.

Ben, a senior, reiterated this idea of organization when he stated, Having an iPad has definitely made my life easier. With a lot of courses, I have 1084 sets of notes, documents, in just the past year. And I'm trying to measure that on paper and this would be awful because I would have to carry 8 folders and three binders! It also keeps my school life organized. 
Ben's substitution of the iPad for folders and binders has helped to make his academic life more organized and convenient. With so much material, the organization feature is a convenience that many of the students appreciate.

Junior Joseph used his iPad as a substitution for a completely different reason. He stated: We have the Student Service app which is an app basically to anonymously tell an administrator, I don't know who runs it, administrator I'm assuming or the principal, if someone is being bullied or someone is in danger or if you need some sort of help. They also send out newsletters about, like suicide prevention month.

Although this is a substitution for telling an adult of an issue, students like Joseph have used it to remain anonymous when reporting an incident. If the app was not available, the students would have to report the incident in person to an administrator. Students would be less likely to report incidents because they most likely want to remain anonymous and not get themselves involved. Since school safety has always been important, having an app available to the students at each school in the district allowed students to report incidents that they see as dangerous or harmful.

\section{Augmentation}

The second level of integration of technology based on the SAMR model is augmentation. In this stage, the technology is still a substitute but it integrates functional improvements. For instance, Maria commented, "We could change the size on the tablet and just use our two fingers and spread it out or make it smaller. On the computer you can't do that because it's just a mouse." This augmentation allowed her to perform at the next level with these functional improvements. When writing on paper, she would not be able to zoom in or out, which makes the tablet functionally better than regular, paper notes or assignments. 
Additionally Victoria, a sophomore, also remarked about engaging activities at the augmentation stage with the iPad.

I think I can show that I can focus more on the iPad like... because when it is on paper, I feel like I have to rush. When I am writing on the iPad, for instance, I can write it smaller for example, like the font, and I can fit more on the page. But on the paper, I have to squeeze in and it's all like rushed. And then I don't like how it looks. Like on the iPad, it's perfect...I'm a perfectionist.

Because Victoria liked writing on the iPad, she may write more or, in her opinion, even better. This makes the iPad functionally better for students like Victoria because of the ability to zoom in or out with ease. Freshman Ray also commented about writing with the iPad. He said, "I typed a lot of essays. Whenever we were able to write it or type it, I preferred typing the essays and stuff, using Google docs. So it's easier to write." For Ray, the augmentation of typing a paper as opposed to writing was easier for him. This small practical difference was a preference for Ray and his learning.

Junior student Joseph echoed this view. He said that "the different types of tools that are on the iPad, like you can do whatever font you want, you could do whatever color you want. This helps me make it mine and personalize it." Joseph felt that using the iPad was meaningful for his learning because he could have control over his notes and learning by changing colors and fonts. These were practical changes that could not be completely performed with activities on paper.

Ben, a senior, commented about the next level of iPad enhancement. He stated:

In the beginning of European history, we had to do these packets for reading guides, and for first semester he [the teacher] didn't have them on the iPad, and so we had to do them 
on paper, and it was awful. I can type a lot faster than I can write. Plus if you have more to say, it is easier to manipulate that into the iPad by just decreasing the font than write on the side. It's so much nicer.

Ben liked having the ability to augment his writing when using the iPad. The simple changes allowed him to enhance what he was doing on the iPad. As Peuntedura (2018) pointed out, the level of augmentation on the SAMR model is similar to the understanding and applying levels on Bloom's Taxonomy. In the example with Ben, he was able to type his notes and make appropriate changes with the font as he needed and used the technology to enhance his work.

A freshman student, Ellen, commented that, "We use it for everything" when referring to the iPad. She also talked about how she had to create a family crest for English class. She explained that she could have used [the note-taking app], but she preferred to choose something else to express herself.

We made this shield thing where you are just supposed to... where it's like your family crest, and you draw six different aspects of your life or traits or life experiences. So I used....the drawing app Autodesk Sketchbook, and you can do layers and erase if you don't need it or you could trace something off of a picture to make it look like you drew it even though you didn't. And then you can add another layer, so it's basically just like coloring in the lines and then you combine them all. So I used that, and it was really helpful. You could have used just [the note-taking app], but I wanted to be fancy.

Ellen went beyond the substitution stage and chose a more advanced app in which to create her family crest. She was able to choose her own avenue in order to complete the assignment that interested her. For Ellen, the technology was replaced, and the purpose of the assignment changed positively with the tool that was chosen in some way. 
During his interview, Joseph mentioned activities that his teachers used that would be considered at the augmentation level with the iPad. In some instances, these activities required student responses that could be used as feedback to develop more appropriate experiences and instructions for the students. Joseph explained, "Some teachers count Kahoot as a homework or a small quiz grade. They can. I have never had it mandatory; it's always been optional because it's like a game." Cassie agreed when she stated, "We will use Kahoot sometimes, but that's just like a fun game." This augmentation allowed teachers to help students to go beyond just reviewing course material by using an interactive game in which they were creating the questions to help their own understanding.

In freshman Ray's situation, he also mentioned class activities that his teachers did that would be in the augmentation stage of the SAMR model, in which the activity goes beyond just substituting the typical activity with a technology activity. He stated, "Sometimes...teachers might put messages through the updates [in the LMS]. Or we get them from the tech department, I think it is about things going on.” By teachers using message updates, they were able to enhance the way in which they conveyed information to their students. Students commented that they usually knew to go to [the LMS] for any class materials, uploads of assignments, and updates to class schedules.

Furthermore, Ray commented, “Oh, and then there is Twitter. I follow several Twitters from the clubs and groups at school." Although schools have always given students announcements, by using technology the schools have now augmented or improved the ability to send announcements to all students as Ray had mentioned. 


\section{Modification}

In the modification stage of the SAMR model, the technology was used to "modify" classroom activities which inspired students to show their learning and understanding by creating new ways to figure out old problems (Portnoy, 2018). Although augmentation and modification seem similar, there is a main difference. While technology allows for functional improvement in the augmentation phase, the modification phase has a significant task redesign.

Maria noted that she engaged in the creation of a storyboard for her English class. She said, "It's [the storyboard] like a comic almost, and we had to do it with a partner. It was a project about mythology, and the myth was about Perseus and how he came to be. We used storyboardthat.com." She did say, however, that some features were easier on the computer, and some were easier on the iPad. This website allowed the students like Maria to create a comic to demonstrate her understanding of the mythology by using the iPad. The activity was coded at the modification level because it changed the activity to make the assignment more personal (Brown, 2018). Maria personalized the assignment by creating a digital storyboard that allowed her to make the choices with her partner of what to include in her explanation of the myth. Instead of just drawing a comic strip, Maria chose the scene and background from templates and made an enhanced story while analyzing the myth for her story.

Sophomore Cassie commented about activities that she engaged in that were coded at the modification level to help her study. "Some people put Quizlets on [the LMS] in certain classes. Like I did that just the other day for Spanish, and other people will post math Quizlets for math equations and stuff, and you can easily use those [for practice or studying]." Quizlet is an app or a web-based learning system that allows teachers and students to create flashcards for studying and learning that can be shared with others. Cassie was engaged in meaningful creation of the 
study cards and then using them to prepare for an assessment. She was able to choose the way she wanted to study and modify what she needed for her own personal learning. In activities on the iPad like Cassie's, students were making an effort to take ownership of their learning.

Ray also discussed activities that he does for class. "We do our homework on the iPads. Sometimes in some classes, like biology, we have to watch a video and take notes. So we have to type it up. So, usually we have to use split screen." This modification allowed Ray to watch a movie and take notes at the same time on the same screen. Before this technology was available, students had to take notes on paper while watching the video or change screens to write on a digital copy of a handout. When students annotate or answer questions using the note-taking app, they are already modifying the assignment with technology. With Ray being able to watch the movie, while having a split screen, using the note-taking app, he has modified the procedure and the assignment for himself. To qualify as a modification, there was a significant task redesign in which he is able to do all of his work, watch the video and take notes, while using the iPad. Students also commented about the ability to import pictures into notes or assignments. This modification allowed for unique products that enhanced the activities that the students produced.

For senior Ben, he commented that he engaged with the iPad in a variety of ways. I have created presentations usually using Google slides...a lot. Because usually when you are doing presentations like that... it requires a couple of videos for school. It [iPad] allows me to do more. So when...for anatomy and physiology...we are trying to make cycles and so instead of just writing words, I can add pictures to it, which helps a lot more visually for me.

By creating these presentations with pictures, his technology knowledge was at the modification stage because he had a student-centered project that gave him a choice of how to learn the 
content using a visual aspect of the course. His presentation also was a significant redesign of a task that went beyond paper or posters.

Sophomore Ursula also commented about items she had been able to create for her classes that were at the modification stage.

Usually I do most of my homework on my iPad. None of it is really on paper because...my classes don't really require paper, so all of it is pretty much on the iPad.

And then turning assignments in on the iPad is really easy too using [the LMS].

The modification of using the LMS for turning in homework electronically allowed students more convenience and easier access to the turn-in process. After a teacher created an assignment in the LMS, the students can submit the assignment to the link listed on the class LMS page. This modification allows students to turn in completed assignments from anywhere, even when they are not in class.

Ursula added, "I like it [iPad] better because you are able to take pictures of the textbook [pages] and put it in your homework for reference, and notes are a lot easier because you're able to take pictures of the board." During the observation of Ursula in her history class, some students were taking pictures of the notes instead of writing them. When I asked her about this in the follow-up interview, she stated the following:

I take a picture sometimes, if I know I can't get it all down, I will take a picture and then split screen and add notes. But sometimes I just write them because it is easier for me to remember things if I write them down. Helps to learn the material.

Ursula used the iPad for taking pictures of material for a variety of reasons. She also demonstrated that she had control over her learning by getting to decide when and if she would take the picture or write the notes. An example of the notes that Ursula took is located in Figure 
5, showing that she wrote what was necessary using her iPad as she listened to the teacher's presentation.

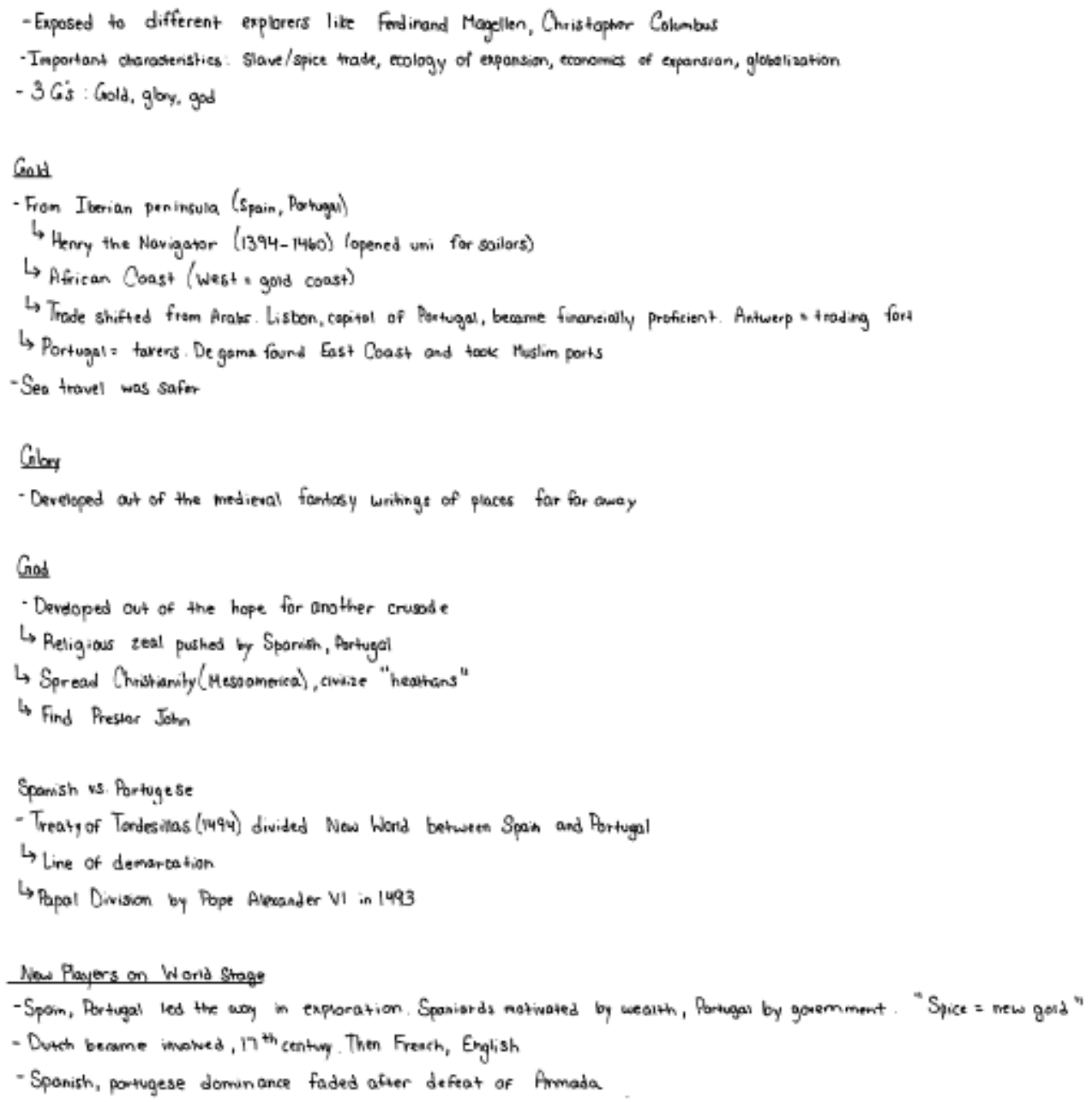

Figure 5. Screenshot of Ursula's notes from class.

Additionally Ursula said, "For art specifically once we finish a project, we take a picture of it using the iPad. Then we will post it on [the LMS page], so everyone can see your artwork all at once all on one page." Ursula explained that the iPad allowed her to use the device to 
express herself in a meaningful way. She also explained that sometimes she was disappointed when she had to do in-class writing assignments on paper because she was so accustomed to using her iPad. She stated, "I feel like it would be easier on the iPad [writing] because you can...I can... type faster than I can write. I feel like you are more efficient when you are typing than you are writing. So....a lot of those essays and stuff in class I'd prefer to do on the iPad."

While watching Ellen during her English class, she demonstrated that she was able to retrieve the practice SAT grammar exercises from the LMS and push them to the note-taking app to begin working. After several minutes, she listened to the teacher as he gave the answers, and she checked her work. She wrote on her iPad the correct answers. During a follow-up interview, Ellen told me "I wanted to have the right answers so I could study from them or use them to refer to because like he [the teacher] said we will have to remember the rules." This modification allowed her to annotate the document in a note-taking app in order to "modify" how she worked with the assignment. She was able to also change colors for corrections. She added, "I can add what I need as I need it. I also can zoom in on [the note-taking app] to put in a little comma here or other punctuation there." This editing was a helpful modification when using the iPad for the grammar exercises as she practiced for the SAT.

Some students mentioned that their teachers had them personally engage in online discussions through the LMS. It was noted that the freshmen had not experienced discussions in the LMS at the time of the interviews. However, the use became more prevalent with the upperclassmen. For instance, Victoria mentioned, "The discussion feature on [the LMS]...we use [it]. And sometimes we have like polls that I answer, the discussion I reply to those things [for class]." 
Ursula echoed the use of the LMS saying, "[The LMS]... you are able to see what is going on in class and then if you have any questions for the teacher, you can post it on [the LMS] for everyone to see, and then someone else might have the same question." Katrina also participated in discussions as well.

[We use the LMS] and the discussion feature in English. There is also this website, I think it's called Today's Meet, and it was usually when we did seminars, and our teacher would put it up on the projector and our teacher would have us login and we would have to comment on the discussion. You could put your questions down there about the seminar or what else you might want to ask them.

This modification of discussion using the iPad allowed students to participate in a silent discussion with other students while an additional live discussion was occurring within the classroom. Joseph, too, used the discussion feature.

My history class does it [online discussions] more than any other classes, but we will be given a couple of questions or topics, and we will just respond with a paragraph. We then need to respond to each other's, and we can 'like' each other's like Facebook. All your class discussions and everything are all on your iPad.

Steven also used the class discussion feature. "The discussion feature in [the LMS] is pretty nice because other kids will post stuff, and we can comment on their things. So that's nice. That is really the only app we use to discuss with other students." With Joseph, he and his classmates were given topics to discuss by their teacher. With Steven, he and his classmates posted questions to their peers about homework or items related to the class, and they answered each other's questions in the discussion.

Adam described another form of learning that was coded at the modification level. 
Well for books I can find any books online, and I can easily transfer it to iBooks or [the note-taking app] and read and highlight, which makes it really nice because I don't have to go out and get the books. And if I have a question or I'm curious about something, I can immediately research it or search it up, which makes it nice.

Adam enjoyed having the internet available to him at all times to aid in his research of interesting information. This modification in technology enabled Adam to have information available whenever he needed it.

Another student, Joseph, used iMovie for class. He stated, "We do a lot of... in English class, a lot of it is visual stuff so we will use the iMovie app and we will make like short films or movies or whatever." This activity was coded as modification because the student created the short film or movie that would be shared with his teacher or other students. He designed it by adding pictures, music, and voice recordings.

Katrina, a junior student, commented about her use of the iPad and specifically the iMovie. "Definitely a lot of iMovies my freshman year. We would do presentations [with iMovie] just to do something quick. I remember one time we did an iMovie for English class, and we had to do a trailer-type thing for the Greek gods." This was coded as modification, too, because she had to create the movie trailer with audio, video and text.

Ray, too, created an original assignment with the iPad. He added that he used iMovie to create a book report for his summer reading. He explained his use of iMovie:

We were able to put your own touch on it like the pictures. And one of the books I read was called Zodiac, so I had my own personal touch on with the pictures for the story. We had to record all the characters...like characterizations [sic], setting, and all the different 
parts of the plot. We had to add pictures and all for each of our stories. It is much easier and instead of having to ... write it out it would be too boring. We had to present it. Ray explained how he took the typical book report and changed it into the form of a digital book report. This changed the way a book report was done beyond a written paper and pencil assignment by using pictures and voice overs. This was coded as modification because it involved combining audio, video, and text into a movie.

\section{Redefinition}

During the redefinition stage of the SAMR model, students used the technology to create something new that was previously thought impossible (Portnoy, 2018). For instance, Ellen mentioned that she had personally engaged using the GarageBand app just for fun, which is a music composing app complete with touch instruments and recording features.

I use that all the time because I take band and chorus, so I like doing that because I like figuring out music with the piano. I just do it by ear sometimes so I've been working on the Avengers theme. Obviously it already exists and stuff, but I like listening to it by ear and then trying to do a cover song, which is basically just copying it. I like doing that. It's fun, and I do that in my free time.

By using the GarageBand app, she was able to generate the sounds of a song on her iPad. The app allowed her to choose the "instrument" sounds that best fit the sound of the song she was recreating which was an existing song. Because she was not following sheet music, this activity was coded as redefinition because she was figuring out the song by ear using synthesized sounds that came from the digital audio library within the app. Brown (2018) compared the redefinition phase of the SAMR model "to the higher-order thinking levels in Bloom's Taxonomy like analyzing, creating, and evaluation." While Ellen was not creating an original 
piece using GarageBand, she provided one example of analyzing a song and recreating it using the app. Because of the higher order skills necessary, her activities were coded as redefinition. Joseph also used GarageBand with his class to create a recording of a story summary. During the observation of him, he and his classmates were asked to read their part of the summary into the voice recorder. He stated, "We had to summarize a portion of the story, which helped us understand the story. It is a hard story." Then the students returned to their seats and needed to use their iPads to render their files and send them to the teacher. Joseph was able to edit the recording before sending. The controls allowed him to increase or decrease the audio speed to make it a clear recording. After recording his piece of the story in GarageBand, he used the software to add appropriate sound effects, and therefore it was coded at redefinition.

Sophomore Rose commented on the activity that was also in the redefinition phase. "I created a website on Weebly for my technology applications class last year. A couple of websites actually and posters and stuff, just for the class." In this instance, the task could not be completed without the use of technology (Brown, 2018) which made the activity at the redefinition level, according to the SAMR model.

During an observation of Cassie, she and her class were using Virtual Reality (VR) goggles to experience a virtual trip of Cambodia before reading their next book.

Yes, it was neat and something different. The tour gave me an idea about Angkor Wat and things that we will be reading about. [The teacher] told us about Cambodia because he was there, but this will give us a bit of a visual, like we were there. I liked seeing the sites first hand.

This is an example of redefinition because it is a virtual field trip that could not occur without the technology. 


\section{Other Emerging Themes}

The study also had other emerging themes which included homework, organization, and collaboration. These themes were mentioned several times by the participants when using the iPad for their learning.

\section{Homework}

When it comes to homework, many students interviewed expressed that they use their iPads to do homework almost every night. Freshman Ray used his iPad to complete his homework by stating the following:

We do our homework on the iPads. Sometimes in some classes we have to watch a video and take notes. So we have to type it up and usually we have to use split-screen. I usually do my homework during study hall when I have my Algebra or English. I can work on my Algebra homework and listen to some music [on my iPad].

Ray added that he likes the ability to be able to do his homework on the iPad where all of his materials are already organized. This allowed him to have everything in one place.

Maria also talked about using her iPad for homework.

I'm not that good at English, and I do need to ask her [teacher] questions sometimes about the homework like when we have to do annotations, I need to know what she means by 'imagery' and where we have to go for it.

In this case Maria worked on her homework on the iPad, but when a question arose, she had the ability to open her email and send a question to her teacher. With all items contained in one place, she was easily able to work and email in the same place.

Additionally Ellen commented on what she does while doing her homework. "Sometimes I use Google...while I'm doing homework on the iPad, and I will randomly think of something 
and I will Google it." Because the Internet is available, as long as Wi-Fi is available, Ellen was able to switch to search for information or just something she had on her mind.

One student used the iPad for homework in the world language classes. Cassie stated:

For homework assignments like in Spanish, we use it [iPad] and it's like an audio of you talking or to submit like a paragraph in Spanish and you help other people fix errors like if you scroll through you can comment on their post.

Sophomore Ursula enjoyed how easy the workflow was when turning in her homework assignments. "Turning assignments in on the iPad is really easy. So most of my school work comes from the iPad." Additionally, four other students in the current study echoed these comments about submitting assignments through the LMS.

\section{Organization}

Another emerging theme was the organization that students enjoyed while using the iPad for their class materials. Organization was an important recurring idea mentioned by the students as being impactful to their learning experiences. For instance, students commented about using the iPad positively for organizing their school work.

Maria stated:

We can use dividers and subjects [in the note-taking app]...... and for a different class we can divide it or use different subject dots, at least that's what I call them. I like to sort it by color, so that I know which notes I need to study and which notes are just on the side and that may or may not be important. I do both different colors and highlights.

This enabled Maria to stay organized with her classes and her time. She would have separate folders for all of her classes with all of them in different places without the iPad.

Ellen reiterated that same idea. 
And the notes, it's really easy because I like stuff when they are color-coded like, with the things we can switch the colors, and it's like 'cool beans.' It helps me organize a lot because otherwise it would be jumbled in each folder. I mean generally I keep stuff tidy, but I lose stuff a lot, so it's easy when it's all right there [on the iPad]. It helps me to be more organized for sure. And I like to highlight.

The idea of having all of her materials in one place helped her to be a better student and have all her study materials together when it came time for an assessment.

Rose also commented that she used the iPad to organize and personalize her schoolwork. I like to make everything really organized so then when I look back at it then I know to pay extra attention to this. And then I make folders too. It's very organized in Notability, so I can get quicker to it like notes, homework, and classwork.

Rose's example of note-taking included everything she described including the different colors she used and how her class folders were arranged. She captured her organization in a screenshot that she shared in Figure 6. 


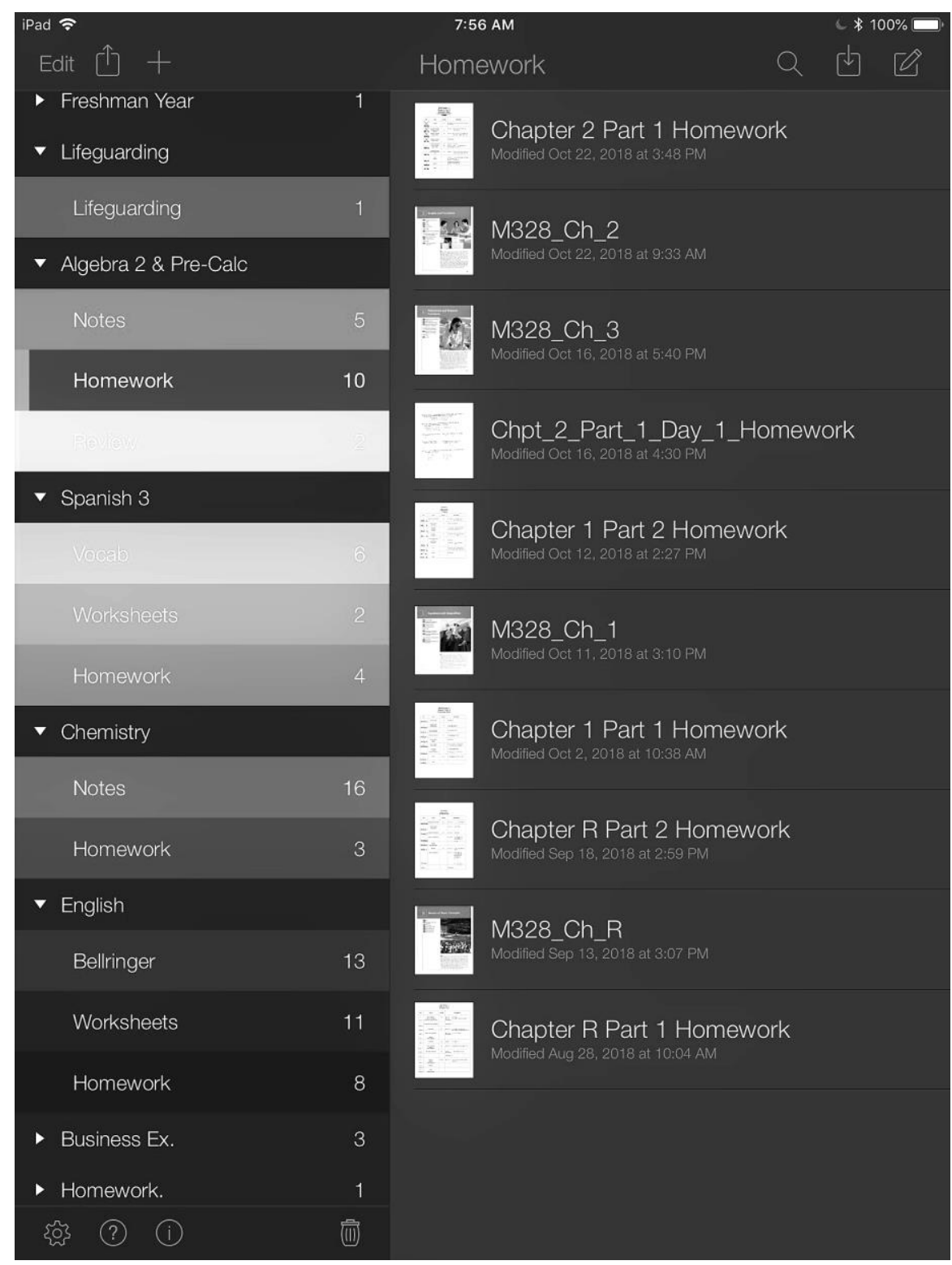

Figure 6. Screenshot of Rose's organization in her iPad using the note-taking app.

During the follow-up interview Rose added that she might take a picture sometimes of the notes when needed. As stated before, she will only take a picture if she can't get it all down. She felt that writing the notes down helped her learn and remember the information. In the SAMR model, these organizational strategies would be at the augmentation level, entitling students to be more organized as they studied. Hailikari and Parpala (2014) found that students who were able to 
organize their study materials and manage their time well were able to experience positive study habits and not allow negative factors to influence their learning.

Steven echoed the ease of organization with the iPad.

What's nice is the iPad, I think, the most beneficial thing about it is organization because literally everything's in your iPad. It is so easy to organize your different apps, like which classes you are going to use certain things, and obviously [the note-taking app] is the main app we use the most so you can organize by subject...put all of the documents into certain things. So it is very nice to set yourself up where you are not going to lose documents, you're not going to lose things. I can also keep track of all my assignments and what I have due and when. It helps me help myself for certain things. It [the notetaking app] kind of automatically color codes for you with the dividers, so like I have it all by subject and then by chapters we are in or units.

The ability to have everything in one place made Steven's documents easy to find. He felt he would not lose any materials because all of them were digital in his note-taking app.

Ben also reiterated the idea of the organization by color.

My notes are in certain colors and that has to do more with me as a person than the iPad. During presentations I will also have different ideas, different photos and colors. [The note-taking app] helps me to organize by subject and then chapter. So I guess I am able to personalize it that way, and express myself.

According to a study conducted by Lei and Zhao (2008), eighty-one percent of students interviewed and surveyed in middle school used technology for their school work. Additionally, they reported that more than $80 \%$ of those students stated that they were feeling more organized, 
and students who typically struggled with organization felt satisfied and successful when using technology to help them with organization.

\section{Collaboration}

Another theme that was prevalent during the interviews was collaboration. Students were able to collaborate with other students through a variety of apps in order to complete assignments and projects. According to a Pew Research Report, teachers were using tools digitally to help students' research topics online. The same study reported that these teachers have students digitally access assignments $79 \%$ of the time and digitally submit assignments $76 \%$ of the time. Other interactive online activities were conducted for learning such as online discussions, collaborative editing using Google docs as well as developing online forums (Purcell, Heaps, Buchanan, \& Friedrich, 2013).

As a freshman, Ray commented about how he collaborated in his English class on a project.

In English class, we had to work on a project, and we had to create a PowerPoint [using Google slides] based off a story that we read together in class. We had to give advice to a character....do it on Google slides. So, we got it, created it, and shared it. I could work on mine, my part, and my partner could work on his part. It was cool, and it was easier instead of just having to go back and forth; we could just do it all together. While I was working on mine, he was also working on his. We never actually had to meet [in person].

The ability to collaborate with other students was another example of them being able to redefine their work on a combined assignment. As previously stated in the analysis of redefinition, the ability to collaborate enabled students to work together to create a meaningful presentation using Google slides. 
Ray was also observed collaborating with other students in Spanish class using a game called Quizizz. Offered as web-based or an app, this game was compromised of self-paced and group games that allowed the teacher and students to review, assess, and engage in the gamified subject matter. This allowed a new level of student participation and collaboration using their iPads because they needed to work together to review and compete within the game. During Ray's class, the students had their own iPads, but they had to work in teams to get answers correct to "race" to get across the electronic board that was projected on the overhead. The students were able to see the other groups and how they were doing and who was winning. They had to cooperate to answer the Spanish questions posed to them.

Maria had similar comments about working collaboratively.

In Spanish class we are doing a project for reflexive verbs, and we have to make a presentation with two other people, so right now me and my group we are...it's going to be interesting on slides and do a performance actually. We are all used to it [slides] by now, and even with students who are seniors, they already know that we have to collaborate and work together [using the share function].

For freshmen with little experience with the iPad, she and Ray were already able to share and collaborate with their classmates to create a presentation or work on a game.

Ellen also worked on a different project collaboratively.

We had to do this science project for testing the toilet paper strength...you know those commercials where it's like the toilet paper can hold these quarters or whatever and then they lift them both. So we had to do them both...like that type of commercial-type of experiment. Then we are all working on a lab report so we all got on Google docs, and 
we shared with each other. It worked out pretty well especially because I was sick the day it was due, so they could finish it.

Although sharing is not new, the students were able to work together and create documents for their science project which was new for these students in that the collaboration was part of the lesson and learning to work together in completing the task. Ellen added, “And it's just kind of dumb if all three of us are doing it rather than if all three of us could collaborate on one sheet." Ellen saw the convenience of collaborating together to achieve the same goal of creating the science experiment report.

Rose also shared that she had done a lot of collaboration, even with people at different schools.

With Google drive, I share a lot of documents like if we have a project. Then I will just share it through that. I also use it for SAT too. There are two SATs [study groups], me and then Matthew who goes to [another school in the district] so we share documents within Google drive. This way we can email each other or share documents and PowerPoint presentations we want to talk about in the meetings we attend.

She shared these documents with a different purpose. She wanted to share SAT materials with a friend, so they were both able to study these materials in preparation for the standardized test.

Ursula, on the other hand, used Google sharing for the collaboration of an extracurricular activity.

For the school newspaper, we use Google docs and then you share it with your editor and with other peers. You can all work on the story together and that's easier than, say, if you did it on paper because then it's like you have the paper, but then no one else has it at the 
same time. So, it's a lot easier in Google docs and probably also like [the note-taking app] because you can email notes from one person to another.

In this instance, she was able to share the article with her editor for approval or edits before she published it for her digital school newspaper.

Katrina agreed about the collaboration aspect, but she used it in a different way.

Recently we had a debate for social studies, and the only way we can all communicate with ourselves is through the Google docs so that you can see what other people type. So we use each other's ideas from there to make the slide that we need and to say the points that we need to get out. So all of us are in Google docs.

Joseph, too, commented about the ease in which to collaborate with the iPad and the use of Google docs for class.

We do a lot of group projects...always done on the iPad. It's really easy to do with Google docs and Google slides with everyone. I can work on my part at home too, and see...like anyone's name would pop up and they would see what I'm typing. Then you can just see what's happening even if you are not with the people. So definitely [helpful] for those types of group projects. Like in my history class. Our topic was Watergate. We had to give the impact it had on the US and the impact on the presidency. I had who was involved and their parts. Doing the presentation was positive for the reasons that we could work on it together but never have to actually get together to work on it. We could see what the other people did when we shared it. Someone else would talk about the reaction by the public and how it was accepted or rejected by other people, etc. Senior Steven also commented on collaborating with his peers. 
Sometimes if we do group projects we can use other apps like Google slides or docs or something, and we can write in our peers' documents and stuff and help them that way. So, with Google slides each student was working on a different slide of the PowerPoint at the same time, which was pretty cool. We were able to make a pretty cool project doing that by adding pictures, text, and just having a nice presentation to display to the class. Ben, as well, commented on the features.

I have created presentations usually using Google slides.... lot. Because usually when you are doing presentations like that, it requires cooperation so you can collaborate and share it with someone or multiple people at the same time. Google docs with sharing to revise a paper. I have done a lot of that. I've also shared with teachers in Google docs having them revise papers and such. But mostly it is presentations with Google slides. By sharing with his teachers, he was able to get feedback or suggestions to make the paper better, which he liked as he tried to improve his writing.

\section{Communication}

Besides collaborating, the students communicated using the iPad. Although the collaboration feature was a form of communicating, the students shared during the interviews that they also used the iPad for communicating with peers and teachers. According to Chou, Block, and Jesness (2014), mobile learning is beneficial, with appropriate implementation, and can dramatically change the classroom from a regular classroom to one that is student-centered to include forms of communication, collaboration, and creative problem solving to help students drive their learning.

Email. One form of communication the students used was email. They expressed that they used this to communicate with their peers and their teachers. 
In this current study, Ray commented on the communication with his teachers.

I would mostly email them [teachers]. Just like when I was sick, I could email my teachers about assignments I had and what I needed to do for homework and what I was missing. I would then email them on my Gmail account. I got all the assignments that I needed so I wasn't falling behind in my classes.

In another instance, Maria talked about using email to communicate with her teacher as well.

I have had to email my foods teacher. I had to ask her for a recipe because in culinary class we have all these recipes that we need to know, and I lost my paper copy, and I couldn't find it on [the LMS]. So I just emailed her, and she just gave me the recipe. Adam and Ellen also expressed having to email their teachers about "homework" or other "things that were going on" in class. They both mentioned that they had missed class and needed to know what needed to be done in order to not fall behind. Although email is not new, the students used the level of substitution in order to keep up with their schoolwork electronically. Because the students had been given a school-issued iPad and email account, they were able to utilize this communication to keep up with their school work.

Next, Maria also used her email in order to communicate with a peer about a class assignment and said it was important to be able to get more information about the assignment. During our storyboard [assignment] we had to email each other constantly because we could only do so much on storyboardthat.com because we weren't members, and we had 6 slides each, and I did part 2, but my classmate, she had to do part 1, and she didn't necessarily know what to do the whole time, so I had to email her to tell her what to do 
and give her some suggestions. And then the same back, I had to ask her because I needed help, too.

The communication with her classmate enabled Maria to provide help to her classmate and get help as they completed the partner assignment.

Rose also commented about communicating with her teachers and coaches through email. Just email. I email my teachers if I miss class for a field trip or I'm just sick or something. I'm rarely sick, but if I was or if I'm in an in-class field trip or I have to go somewhere or I didn't get the homework, or I forgot to turn something in but I did it, I will email them about that. Usually they [teachers] email back within the day, like sometimes I will email my coach and tell him I'm not going to be at practice because I'm sick or I'm not feeling well. And so she will email me back and, of course, she will say it's fine and just feel better or ask, 'When do you think you are coming back?', something like that. Coach will also push out emails about 'we have a meet on this day' and make sure you do this and this and eat healthy. Every month we have had an email. Victoria used email a little more with her friends. When my friends aren't here, like in math or something, I usually email them the notes or what we did. And I email the teachers when I miss school [asking] 'what did I miss?' or any worksheets or when I'm not going to be there.

Cassie also used email to communicate with friends, but it was to share pages from class with them.

I will email my friends a lot. Recently there was an assignment we had to read pages from the science textbook, but it wasn't loading for anyone. So, I went in and asked my teacher if I could take pictures of the textbook pages. She said sure and then a bunch of 
my friends, who hadn't gotten pictures of the text wanted me to send the pictures to them. So I could send it to them. I could send them all the pictures and they would all get it. So I was also able to collaborate with them and say here is what you need.

Ursula also mentioned email as part of the need to communicate for her activity and class.

We use the email [on the iPad] to set up a lot of interviews for the school newspaper. Then in chemistry if your lab partner has the data and you have the one part, it is just easier to email notes directly, and they can open it up and edit it if they want to. And also with the entire Google system, you can share via email and edit. I have emailed if I'm not going to be in school for a few days because I got sick last year and I missed like 2 or 3 days, and I then just emailed my teachers and I was just like 'Hey I'm sick and when can I make this up' or like 'if I turn this in will it be late or will it count against me,' so that made it a lot easier, so I was at home and I was able to communicate with them and they were at school. So, that definitely helped out in the long run because you could find out what you could skip out on.

Katrina also explained her communication and the importance of keeping in touch with her teachers when she is absent.

Email is the one way I communicate with everybody. It depends on the subject, but sometimes I will know in advance of the days I know I won't be at school, so I will email the teacher that night and be like, 'Oh like do I need to turn this in this day or do you want me to turn it in the following day? When do you want me to catch up for my work, too?' Or if the teacher is not there that day and I have a question, and I needed her to be there, I will email her and be like can I meet up with you in the morning or whenever you 
are free? And they are usually like, 'Yeah sure.' And I will just go in and stuff for this class. Or 'can you help me out with this?' And, too, with my friends, there was a time where my phone broke and I didn't have a phone so I would have to email my friends and be like, 'Can you send me the notes?'

Joseph remarked about using email as well.

I will miss a class, I would say every two weeks because I have to go to a doctor or something or sometimes I oversleep, because you know I'm human. Sometimes I oversleep through 1st period. I will always email and they are sent back and forth. Phones are prohibited. Sometimes I will email a peer and say, I'm confused on number 6 like, can you show me your work for $\# 6$ ? You will get the work for \#6 or, that's if they are not in a different class or something. If I know that I'm going to miss class that day, I can email my friend.

Steven, too, mentioned the use of email to communicate.

I email my teachers a lot. Any time I have a problem or a question, I will just shoot my teachers a quick email and normally will get a pretty quick response. So it's nice to get the feedback right away, and if we didn't have the iPads, it would be a lot harder to get in touch with our teachers. Email is nice.

Additionally Ben mentioned, I am constantly talking to my friends about different assignments that are due, and I always ask for help sometimes via email. I do email my teachers when I need help. So that is also a big plus. The email addresses are loaded and easily populated. Although email has been around for numerous years, to these students, it is still an important form of communication to have when reaching out to teachers and other students. 
Announcements and discussions in the LMS. Another recurring topic within the theme of communication is the use of the LMS for announcements and discussions. For instance, Ray commented, "Sometimes we've used [the LMS]. Teachers might put messages through the updates. Or we get them [updates] from the tech department, like it is about things going on [in the school]."

Ursula also remarked about using the LMS for communicating. "The teachers will share resources through [the LMS] with the students.” Because students each have the LMS account and a page for each class, most students can get information from their teachers via the LMS. There is an email feature within the LMS for each class as well as an "updates" section where teachers post information for students in that specific class. Students can turn on notifications too, so that they are alerted when someone posts an update or sends them a message.

Rose, too, used the LMS feature for communication.

Once in a while, usually I use [the LMS] because if the teacher doesn't answer [me via email] some of the other students will, like if they get it [my question]. I have joined all of [the LMS] classes for all my clubs, and then I just check the updates every now and then. I am also a mentor for freshmen, and they push out the info we need to know. It's definitely a lot easier in the update section, and you just have to look in one place for all your information. So, I don't have to go through each individual class because sometimes I might forget to check this club or page.

Also within the communication theme and as previously mentioned, the students remarked about the capability to participate in an online discussion within the LMS. In this feature, the questions and answers were presented to anyone who was part of the LMS class or group. The discussion was generated by teachers or students and could be formal or informal. 
Maria mentioned, "We have a discussions part on [the LMS]. You can start a discussion and you can discuss with other people." She also added, "In Spanish class, we discuss like what we are having trouble with and what we think of our student teachers because they want our opinions about certain things and how they can improve themselves."

Additionally Adam commented, "Yeah like [the LMS], we do discussions. We even do discussions in class so if you want to post something for the discussion because you don't want to talk in class. Some teachers also have a link in which to ask questions during class, which is nice because the kids who don't want to express themselves in class with their voice and can type it out." Victoria also uses [the LMS] to communicate. "Sometimes we have like polls that I answer, the discussion feature on [the LMS], and I reply to those things."

Other forms of communication. Besides traditional forms of communication like email, the students commented that some will communicate via social media and use FaceTime or Instant Messenger.

Freshman Ray commented, "There is Twitter. I follow several Twitters from the clubs and groups at school [to get information]." Rose agreed stating, "Some clubs use Twitter, so I followed them on my own personal account. And then, I guess just... they get calendars like I know swimming does, they give calendars...like we have practice in the morning this day or after school this day. I guess they would just have to do that. They just publish the calendars on [the LMS], too."

For Adam, he used Instant Messenger on the iPad to communicate. "With my friends, I ask them a quick homework question or in school when I can't take out my phone, I can quickly ask them on the iPad with iMessage. So that's nice." 
Steven echoed the use of IM stating, "I also have iMessage on my iPad, so I will text my friends because some teachers won't let you use your phones. If I have to communicate with one of my friends I will send them a quick message."

Ben used a combination of methods to communicate with people saying, "IMessage, and then freshman year it would have been through email, and then once we got our iMessage, I definitely transferred to that." He completed the Digital Citizenship course freshman year, but added, "I don't use FaceTime on my iPad."

Not all students have the iMessage capability on their iPads. Students were required to complete a digital course in order to prove that they were responsible digital citizens in order to receive this and other features on their iPad. According to the technology coordinator, "All schools in the district offered a Digital Citizenship course written by the coordinators in conjunction with Common Sense Media. Once students completed the ten hours that the course took, they were able to get iMessage, Airdrop, and FaceTime" (technology coordinator, personal communication, October 18, 2017). If the students completed the course, they were awarded these other applications.

Some students completed the class but did not find the features useful or necessary. For instance, Victoria said, “I don't use them because I don't know how. I don't know how to login, in order to get them. So it just doesn't let me login, even though I did the Digital Democracy course to earn them."

Adam found it very helpful to complete the course.

IMessage lets me contact friends that I need to for homework help or stuff like that. I went through it so I could get iMessage and we got FaceTime. I thought it was pretty easy. It takes time because there is a lot of parts, but once you do them, it is really easy. I 
wish everybody had iMessage. Also, iMessage and FaceTime allow you to contact school people, and it's easier because everybody's contacts are available to you. Also with my friends, I ask them a quick homework question or in school when I can't take out my phone I can quickly ask them on the iPad with iMessage. So that's nice. Joseph had a different response to using the iMessage. You can contact anyone at any time of the day. I got the ability with iMessage through doing that thing [Digital Citizenship course]. At least 60-70\% don't have it on their iPad because nobody did it. Everyone was like 'oh they will just give it to us when we're sophomores.' And now it's too late. Because they didn't earn it their sophomore year. I don't really use it because I'm not talking about anything but know that the school can access every text message that I have. It doesn't have to be bad, it could just be personal. It's just weird knowing that your administration has full access to your messages.

Joseph did not want to use the iMessage as others did because he had some privacy issues since the iPads are district owned and controlled.

\section{Inconsistencies}

There were also some inconsistencies with the students' data that reflected that the use of the iPads was not completely positive for all of the students' experiences. One student Ray brought up the issue of glitches with his iPad. During the observation he was having trouble with his iPad and his teacher assisted. At the follow-up interview he said he was having trouble with the note-taking app. He said, “I needed to download the latest update. I haven't done that yet. Could be why things crash.” Therefore, he noted that it was important for him to understand that maintenance of the iPad was a priority in order for the device to continue to run smoothly during 
all of his classes. Students, like Ray, did not always know how to trouble-shoot when there was a problem with the iPad not working properly.

One student Maria was observed in her math class using the iPad. When questioned in the follow-up interview she said that she preferred to do her math on paper rather than the iPad. She stated, "I just like writing it down on paper because it helps me remember better. Well I actually have to read over it again because I don't want to erase [when it's on paper]." Maria explained that she feels she is more careful on paper. However, during the observation of her in her math class, she used the iPad. When questioned about this she stated, "Yes it helps to see it when he does it, so I have mine like his and can compare." She wanted her page in the note-taking app to look just like her teacher's looked when he projected on the overhead even though she preferred to use pencil and paper when doing math problems.

\section{Issues and Improvements}

Another theme that students commented on were improvements for the use of the districtissued iPads from their point of view. Several students brought up the restrictions and inability to access the App Store.

Rose commented about the restrictions.

I do wish we could download our own apps even if it is not Netflix but just access to other apps that we wanted to use. I might want to use something here and now, and I just can't get it. I get why, but it is not something I would do, but I feel like I am being punished for something. Maybe not punished but because other people would use it in the wrong way, not everybody can use it. I think that is another reason why we had to do that thing freshman year [Digital Citizenship course]. 
She then offered some suggestions as to what could be done in order to allow students to have access to the App Store.

Maybe a survey that tells what you would use it for or how you would use it or even a timer on our table where it locks the other apps when you are in an actual app. That [grades] could be an incentive. Like if you get a 3.0 or higher, you can get it [the App Store]. You can get specific apps and stuff.

Joseph also commented on the restrictions being annoying because it hinders his research.

There's certain apps that you can't connect to. The iPads are restricted, so we can't search whatever we want necessarily. It's also kind of a bummer if you wanna research, like some parts of high school are more serious topics, and you can't do your research on that because it's all restricted, like abortion or drunk driving.

Joseph referred to using Google or other search engines for research that has restrictions. However, students have access to the school's databases that are not restricted for certain research.

Joseph had a similar suggestion as Rose to improve the iPad usage for students. I think the restrictions, and this is my student perspective, are a little bit much, so everyone is innocent until proven guilty, so if you don't do something with your iPad and you're getting good grades, maybe if you have more than a failing class, you should get restrictions. If you're getting good grades and you're doing what you need to be doing academically on the iPad and you're a good student and you're not getting yourself in trouble and everything, there should be no reason why we shouldn't be able to go and watch Netflix after you do your homework one night on your iPad. Can't they earn 
unrestricted? There could be a school policy, like 3.5-4.0 [grade point average] you get no restrictions, and 3.0-3.5 you get everything but this [item or app]. Something that they could earn, and it would be motivation. Kids want to use their iPads. They want to actively use technology that has been given to them for free.

Because of the current restrictions, students do not have access to the App Store. If students needed an app for class, it is put into the school's self-service app for students at teachers' requests.

Steven also commented on restrictions. "My freshman year was the first year they started restricting the iPads, so we can't get our own apps or anything, but we can still go on Safari and they will block some stuff." He did not have any suggestions necessarily; however, he did say that when it comes to distractions it "helps so students can't be on Netflix and other apps. I feel like there are a lot of students who get distracted and stuff, but for the better students even if they get a little distracted, they'll probably be fine."

Victoria also remarked about restrictions that led to important information being blocked for class.

I'm in early childhood class and when we are looking up something about babies or when we learned about conception, then that information was mostly blocked, I mean the websites that told us about that information. I don't remember exactly what it was, but there was some times where the teacher was like 'Oh go on this website to get the information' and we went on it, and it was blocked for some reason.

The restrictions, although well-intentioned, can become an issue as the students use their iPads for necessary class research. 


\section{Summary}

The results of this study were explained in this chapter. The themes were derived from and related to the SAMR model of technology integration, and the students showed how they used different iPad applications that would be considered substitution, augmentation, modification, and redefinition levels of the model. Besides the SAMR model themes, there were other emerging themes from the students' comments, which included homework, organization, collaboration, communication, and issues and improvements.

The next chapter will show how the research study answers the research questions, and provide conclusions and implications of this study. The chapter will also make suggestions for further research. 


\section{CHAPTER V: CONCLUSIONS, LIMITATIONS, AND RECOMMENDATIONS}

Technology use has become an important part of education. But, the technology, like iPads, are only effective if they are used by students, and teachers are effectively trained to implement the devices (Hixon \& Buckenmeyer, 2009). This chapter connects the data from interviews, observations, and work samples from Chapter IV with the literature found in Chapter II to provide conclusions to research questions. Also, this chapter presents the results and conclusions that can be drawn from the interviews, observations, and work samples in regards to specific themes that emerged from analyzing the interview data. The goal of this chapter is to provide the key findings and show relationships and connections to the students' answers about their iPad usage and examine the possible implications for future use and future studies.

\section{Restatement of the Problem}

This study looked at the way a one-to-one iPad initiative impacted students' learning. Students' interviews, observations, and work samples provided data about their iPad use and how they felt about using them. The study used the constructivist theory as it related to informing about the complexities of the students' learning while using the iPads. Additionally, the SAMR model was used to compare the implementation of the iPad with the level and difficulty of the activities. This chapter provides results from the research questions based on the data collected as well as implications for future research.

\section{Research Questions and Methodology}

The study was conducted to discover how a one-to-one iPad initiative impacted students' learning. It used the qualitative case study methodology that included interviews, observations, and work samples. The methodology included interviews with participants, recorded field notes, observations of participants in classroom settings, and analysis of work they produced. This 
information was then coded and reviewed for patterns and themes. The following research questions were used to guide the study:

- How does a one-to-one iPad initiative impact high school students' learning?

- How are the iPads used in a way that is meaningful and worthwhile to learners?

- In what ways are iPads used to engage student interest?

- How are iPads used to foster communication and collaboration?

\section{Study Discussion}

Students generally expressed that they liked using the iPads for their classes. They liked the convenience of having all of their materials in one place, which made writing papers and studying easier. Research on the iPad use and adoption strongly suggested that digital devices like the iPad had a positive effect on students' learning by increasing inspiration, excitement, innovation, and efficiency (Clark and Luckin, 2013).

The results show the influence of the constructivist theory. Based on the constructivist theory of individual learning (Vygotsky, Hanfmann,\& Vakar, 1962) and social learning experiences (Piaget, 1964), the students demonstrated that they have enjoyed engaging in both personal and group interactions with the iPads. Using the various forms of communication allowed them to interact with peers and teachers to gain understanding of the lessons while interacting socially. However, while using the iPads individually, they have learned about using the devices for their class lessons thereby individually gaining a new understanding of the course content. They have also been able to interact socially when using Google docs and slides to create a meaningful project by using the iPads. The students also enjoyed being able to collaborate while using the devices both in and out of the classroom. 
The results also indicated that the students engaged with the iPads and implemented the four different levels of the SAMR model with the teachers' activities. Given that the substitution level is the lowest level of the SAMR model, the level does not necessarily mean that there was less engagement or less meaningful use of the iPad. Certain activities may require an easier substitution than other activities. Also, the redefinition level was used less frequently depending on the students' level of understanding and the goal of the lesson.

Also, in analyzing the SAMR models, most of the students' activities on the iPad were at the substitution level. Augmentation and modification, although similar, are different in terms of the level of transformation. With augmentation, the technology adds functional improvements to the assignment or task; with modification, the technology helps to transform or significantly change the design of the task. In order to access the full potential of the iPad, teachers should offer more activities and lessons to students at the modification and redefinition levels. Since some teachers have been teaching without the iPads for so long, they may not realize all the possibilities that are available to help students create something meaningful at the redefinition level. By offering more opportunities, the students will have far more ability to think critically and engage in creative production. Regardless, the use of technology was dependent on accomplishing the instructional goals for the class and should be used to enhance them appropriately and effectively, rather than reach a particular level of SAMR (Hilton, 2016; Johnson, 2013).

\section{How Does a One-to-One iPad Initiative Impact Learning?}

With the help of their teachers, students in the study were beyond the basic use of the iPads and were able to create, collaborate, communicate, and integrate using their devices. The students knew beyond just basic searches on the internet as observed in their classes, from their 
interviews, and from their work samples. The students also demonstrated that the iPad had a positive effect on learning. Although the students recognized that the iPad can be distracting at first, the benefits, according to the students, seem to outweigh the disadvantages. Three students even added that they would like more opportunities to use more features on the iPad by accessing the App Store, which is currently restricted.

All of the students talked about the ease of using the LMS, a learning management system, which allowed teachers and students to manage and share content for their classrooms. All of the students said that they were able to use the LMS to find assignments and notes that were necessary for class. The LMS impacted their activities and learning by helping students stay organized because they had one place in which to go to find assignments or check for class information. Three students also commented that their club or activity also had an LMS page for its members that included information about meetings or practices.

The students expressed that they were more organized with the use of the note-taking app when it came to their notes and assignments. First, they used the app to fill out homework or other assignments that were pulled from the LMS. Also, one student commented that she had all of her homework and assignments in one place, and therefore, was more likely to turn them in and not lose assignments. Another student also expressed that being more organized helped him to be a better student when it came to studying and learning from his materials because everything was all in one place. Finally, another student found that organizing made her a better student because she would not lose information which included notes or homework because everything was digital and all in the note-taking app.

The students also expressed the ease in which to use the LMS. First, the LMS enabled them to submit the assignments through an electronic submission process. All students had been 
taught how to submit an assignment to a link that was created by the teacher. Freshmen students who were interviewed had fewer opportunities to use the submission process but still knew how to submit. Next, they also appreciated the ease in which to get information for class from the LMS pages that teachers had set up. Since most teachers used this platform, the students were familiar with its functionality and accessibility, which made the transition from class to class easier when locating information, getting notifications, receiving assignments, and being aware of due dates. This supports what Frey et al. (2015) found with their iPad deployment study. Their study found that using an LMS easily enabled students to have access to class content throughout the day and even after school. This enabled students and teachers the ability to exchange content.

In addition, all students commented that they had collaborated on a project with a group or peer using either Google docs or Google slides. This had impacted how students worked on the projects together because they were able to work on the group project without being in the same room. Having an iPad offered opportunities that these students would not have had otherwise because the iPads were issued to them by the district.

Since students were able to collaborate on projects, group work was easier. They liked the sharing feature and could see that the other person was doing his or her own part of a project or presentation. The sharing feature allowed students to bring collaboration to a new level that helped keep all group members accountable. Besides Google docs and slides, most students had experience with using iMovie, which allowed the students to create a movie or trailer either independently or with a partner.

Also, students used the iPad for their own personal interests that were not necessarily school-related. From doing an internet search for college majors to using an app for band, the students were able to navigate the devices for their personal interests and enhance their own 
learning needs. The students also commented that the LMS pages were helpful for extracurricular activities because sponsors and coaches posted updates and announcements.

Besides interests, the students used the iPad for other activities. For instance, one student commented that he used his iPad in order to report a bullying situation through the school safety app. This allowed him to remain anonymous when reporting an incident. Also, students expressed that they could have meaningful discussions on the iPad through the LMS app. The students enjoyed when their teachers used the LMS to post a discussion that allowed students to engage in online discussions in which they could write their own opinion on a posted topic. One student even said that he discussed more when he could type the response into the LMS. A study by Thomas (2002) found that engaging in online discussions helps to promote higher levels of cognitive engagement and critical thinking.

The study confirmed what researchers found at Ryerson University in their "Project iPad." Although their participants used a computer as an essential part of their educational life, they found the iPad was an influential tool that aided in collaborating, organizing, and learning regardless of their area of academic study (Eichenlaub, Gabel, Jakubek, McCarthy, \& Wang, 2011).

\section{How Are the iPads Used in a Way That Is Meaningful and Worthwhile to Learners?}

Learning can be made meaningful when students are able to express themselves in meaningful ways. The students in the study used the iPads in various ways that made them meaningful for them. First, students liked the ability to organize and color code notes using the note-taking app which has a tab feature to categorize the notes as well as a folder feature.

Students felt that this made their notes personalized, and therefore, they were more meaningful to them when studying because everything was organized by class. Also, the students liked the 
ability to have all of their work with them at one time. Since most of their information was on the iPad, they always had everything that they needed with them at all times. This was important in case they were reading a book or working on a paper, since they always had those items with them.

The students also found that the LMS and the note-taking apps went well together to make learning meaningful and worthwhile. Since all of their classes could be accessed from the iPad on the LMS, the students knew where to find materials that they needed. All twelve students said that they could find their teachers' information from class, the assignments, and other needed resources within the class LMS page. This made it very convenient when they had to sit down to do homework. From there, the students took the assignment and pushed it to the notetaking app to complete the assignment. Although this is at the substitution level for paper, the apps made the process of completing work much easier. The workflow of retrieving the assignment from the LMS, completing it using the note-taking app, and then submitting it back to the LMS all made the process simple and convenient for the students.

Students also found the discussion feature in the LMS meaningful. The students in this study commented that the online discussion feature allowed students to give their opinion on a topic, especially if they were too shy to comment in class. This allowed them to still give meaningful input to the class topic.

Students in one college study realized the power of the iPad was not only to "consume information" but also to "produce new content" like the discussions. The students in the current study demonstrated that they were also able to "customize effective time-management strategies" and "streamline tasks" as well as "alter their academic workflow" just as in the study of the college students (Eichenlaub et al., 2011). 
One student found the iPad meaningful for additional functions. He said that the iPad was useful for adding pictures into his notes to make them more visually appealing. The ability to add pictures to his notes helped make the information from class more meaningful for the student in order to learn and understand it. Calvert (2015) found that students should be encouraged to add videos, pictures, and even audio to any task which helps integrate technology at the modification level with that task.

\section{In What Ways Are the iPads Used to Engage Students' Interests?}

Because the iPads were restricted, the students commented that sometimes they were limited when they were conducting searches of their own interests. Some sites had been blocked unintentionally as the restriction tried to block them from inappropriate or unintended sites. However, the school and the district provide databases that will help with school-related searches when researching sensitive topics.

The students also expressed a variety of ways in which they engage with the iPad for their own interests. First, many students said they used it for their extra-curricular activities. The students were also able to keep in contact with their sport or activity through the LMS pages that were set up by the coach or sponsor. Students made comments that they knew where to go to check the practice schedules or for any updates about the meetings or canceled games for their sport or activity.

Students also enjoyed being able to use the Internet via Safari to look up something that they were interested in knowing. One student used the Google search while in class to look up the topic being discussed. This allowed him to go back and continue to research the topic that interested him from class. This helped him continue to learn about class-related items that he found interesting and wanted to explore on his own. 
In a study conducted by Chen, Guidry, and Lambert (2010) on student engagement and online learning, they found that students who utilized the Internet and other online technology are more likely to engage in a deeper understanding and higher order thinking. Another student's comment about using Safari allowed her to pursue other interests that she had on the iPad. She enjoyed looking at shopping sites, sites for math help, and using the online library for digital books. Another student also used the Internet for information that interested him, which included YouTube. When adults allow students to move away from formal instruction in school, they search online for ways in which to learn their own life lessons about societal rules, their peers, and other interests (Lee \& Kim, 2014).

At least three students commented that they wanted to be able to download their own apps or have access to the App Store. However, because the iPads were restricted, the students were unable to access any apps that were not provided through the self-service app. Students expressed frustration about this because even simple searches for class had also been blocked. From their point of view, this prevented meaningful searches because the students had limited access to the Internet from their iPads.

\section{How Are the iPads Used to Foster Communication and Collaboration?}

All students interviewed reported using the iPads to communicate with teachers and other students. Each student had been issued a district email address that was set up on the iPad. All 12 students stated that they could easily email their teachers if they had a question about the class or an assignment or ask about what they missed if they were not present for class that day. Some also commented that they appreciated the ease in which the email allowed them to contact a teacher and the speed in which the teacher responded. This saved time finding out what was missed or getting answers to questions about class. Besides emailing about missed classes or 
assignments, two students reported that they easily communicated with their teachers about setting up a meeting for before school or ask about missing grades or late work.

Nine of the students also mentioned that they used email to communicate with classmates as well. Their communication was often about homework assignments. Additionally, six students got their communication from the LMS. These students reported that some of their teachers used the LMS to announce what was accomplished that day in the course updates section, or the students knew to check the course for updates if they had missed class. One student reported that she could communicate directly with the teacher through the LMS as another option besides email. Communicating using mobile devices has become an important part of being digitally literate and helps to support students' achievement (Crichton, Pegler, \& White, 2012).

Besides using the iPads to communicate, the students also reported that they used them to collaborate on projects. All of the students described collaborating on writing assignments using Google documents or working on a presentation using Google slides. The students liked the ability to work independently on their part of a project while still working collectively with a partner or group. The collaborative apps did not require the students to be present in the same room and allowed them the freedom to work on their own time and in the comfort of their own home. The students also commented that they could share information with others using the iPad. When they collaborated on a Google slides presentation, one student started the assignment and first "shared" it with the other group members. The students knew how to do this and could easily collaborate on projects with their peers. In a study by Chen et al. (2010) about online learning of college students, the researchers found that students who used online technology and the Internet showed positive levels of active and collaborative learning and were able to engage in higher order thinking and be more reflective in their learning. 
During the interviews, two students also stated that they had shared their papers with their teachers for feedback. They had done this to get some suggestions from the teachers about how to improve their papers or even to get some organizational suggestions. This collaboration was also done outside of the classroom.

At the time of the interviews, three of the freshmen students had not had opportunities to collaborate on projects or assignments with other students while in high school. The upperclassmen, however, had more opportunities to collaborate because they had the iPads for a longer period of time.

In a study conducted by Chou et al. (2014), the researchers found that participants were more proficient in creating projects and finishing assignments when using a device. They also found that there were a variety of multimedia apps that could help the students produce assignments and/or projects with features that are not available with just paper such as pictures, presentations, and even screencasts.

\section{Implication of Practice}

This study has found that an iPad initiative was very successful. According to the students, they have been given a variety of opportunities in which to use the iPads in many ways. First, they had been taught how to collaborate with their peers using Google platforms like slides and docs. This allowed students to work together on a project without actually being together. Next, the iPad enabled them to create something new. Many had experienced the opportunity of creating a project on iMovie or even the note taking app. This gave them some editing features and mini movie making skills that students might not otherwise have had the opportunity to do. Additionally, the students liked the simplicity of the LMS and that all teachers used the same 
platform. This allowed teachers to share information about classes, and students knew where to find the information as well as communicate about that information within the app.

The study also found students were comfortable using the iPads for a variety of activities. Even students who had not previously had iPad experience prior to high school said that they learned freshman year from their teachers. Teachers helped them join the Schoology pages and helped them to find information that they needed for classes. For Frey et al. (2015), their study stresses that teachers need to learn to integrate the technology as an instrument that should be used to complement their high-quality instruction.

\section{Limitations}

This study had a few limitations. First, the study was limited because of the number of participants. Ideally, the study would have had more students from each level, freshman through senior. However, not enough students agreed to participate in the study to make that idea feasible. Also, some students did not finish the appropriate paperwork; therefore, those students could not be considered for the study because consent needed to be secured in order for the student to participate. But, the small number of participants allowed for conclusions to be drawn about the students and their iPads in this school.

Another limitation to the study was that the data could not be generalized. With this qualitative research, the data was only able to explain the experiences of these students from this school, and the study was not generalized beyond this scope that these students shared.

Finally, the study was also limited in what the students shared. The students did not always know how to respond to the questions asked about their iPad activities or about using the iPad. Some talked about apps that they liked using as opposed to the apps that were the best for their learning. 


\section{Recommendations for Further Research}

One area for future consideration would be to further study the SAMR model levels and one-to-one iPad use. As students use more technology, different levels should be considered beyond the substitution level. The SAMR model should be used as a guide to help teachers and students create projects and learn at a higher level. Although the substitution level may be appropriate for new concepts, research needs to be considered on how to help teachers and students move to more higher-order activities that show critical thinking and understanding. However, as students become more comfortable with the concepts being taught, higher levels like modification and redefinition are preferred in order for students to show their understanding.

Although this study did not focus on gender, race or socioeconomic status, additional studies might consider these areas. A study could be conducted to discover if girls or boys are more successful with an iPad initiative. Consequently, a study could consider race and differences among students of different ethnicities and their views of an iPad initiative. Finally, a look into the socioeconomic status and the impact an iPad initiative has on those who may have economic challenges. Can an iPad initiative help close the achievement gap as well as the technology gap?

Also, future research could be conducted on the professional development needed for teachers to incorporate more levels of the SAMR model into their one-to-one classrooms. Since this study focused on the students' perspective, additional research could be led about the teachers and their perceptions or needed development to help them implement higher levels of the SAMA model to challenge students to create products that transform learning at the redefinition level. 
Finally, the students in the study also liked the ability to have online discussions using the LMS. The students who had used the discussion feature liked having the opportunity to give their opinion about a class topic and interact with their classmates. Another study could consider the benefits of online discussions besides giving their opinion.

\section{Final Thought/Conclusions}

For over five years, the school district of Century High School has been implementing one-to-one iPads with their students from freshmen to seniors. The 12 students interviewed clearly demonstrated how to use the iPad for their personal and educational literacy practices. Based on the research questions, the conclusion can be drawn that students are properly equipped with the skills to use the iPad to navigate the devices for their academic and personal learning. Students were able to learn to create items on their iPad from movies and trailers to slide presentations and written work. The students also understood how to navigate the Internet to find information that they needed, whether it was for class or for a personal interest that they had. They demonstrated the fundamental skills of digital literacy by employing reading and writing across the various platforms that the iPad had to offer. Furthermore, they enjoyed using the notetaking app on the iPad because it allowed them to organize and categorize their notes into folders as well as color code and personalize their notes and homework.

Because technology skills are an important part of the future, the students interviewed seemed well prepared for college and other digital literacy tasks because they have had the iPad experience. Although some students prefer paper for some activities like test-taking and math computations, for the most part they felt that the iPads were helpful since they had so much information at their fingertips when connected to the Internet. The iPad initiative also helped those students who did not have computers at home, and it may even close the achievement gap 
for those who are less fortunate, now having the fortune of the iPad and all of its educational capabilities.

Students were also given experiences with the iPads that are necessary for college. Students were able to collaborate on Google slides or docs with a partner for a presentation or a partner project. Several students also had the experience of working with iMovie to be able to create and edit a movie or trailer. This helpful experience allowed them to showcase their creativity as well as learn a platform that involved editing and recording.

Students also commented that they had experiences with other apps such as Sketchbook and GarageBand, which allowed the students additional opportunities that engaged their personal interest but that could be used for school as well. These experiences might just be the spark that a student needs to find the right career opportunity. 


\section{REFERENCES}

Allington, R. L. \& Gabriel, R. E. (2012). Every child, every day. Educational Leadership, 69(6), 10.

Alvermann, D. E., Gillis, V. R., Phelps, S. F. (2013). Content area reading and literacy: Succeeding in today's diverse classrooms. Boston, MA: Pearson.

Alvermann, D. E., Hutchins, R. J., \& McDevitt, R. (2012). Adolescents' engagement with Web 2.0 and social media: Research, theory, and practice. Research in the Schools, 19(1), 3344.

Aurini, J., Heath, M., \& Howells, S. (2016). The "how to" of qualitative research. Los Angeles: SAGE.

Barrs, M. M. (2000). Gendered literacy? Language Arts, 77 287-293.

Baxter, P., \& Jack, S. (2008). Qualitative Case Study Methodology: Study Design and Implementation for Novice Researchers. The Qualitative Report, 13(4), 544-559. Retrieved from https://nsuworks.nova.edu/tqr/vol13/iss4/2

Bebell, D., \& Kay, R. E. (2010). One to one computing: A summary of the quantitative results from the Berkshire wireless learning initiative. The Journal of Technology, Learning, and Assessment, 9(2).

Berkeley, S., \& Lindstrom, J. H. (2011). Technology for the Struggling Reader: Free and Easily Accessible Resources. Teaching Exceptional Children, 43(4), 4-55.

Biancarosa, G. (2012). Adolescent literacy: More than remediation. Educational Leadership, $69(6), 22$.

Black, R. W. (2009). Online Fan Fiction and Critical Media Literacy. Journal of Computing in Teacher Education, 26(2), 75-80. 
Blok, H., Oostdam, R., Otter, M. E., \& Overmaat, M. (2002). Computer-Assisted Instruction in Support of Beginning Reading Instruction: A Review. Review of Educational Research, (1). 101 .

Bozack, A. (2011). Reading Between the Lines: Motives, Beliefs, and Achievement in Adolescent Boys. The High School Journal 94 (2) 58-76.

Bromley, K. (2012). Using smartphones to supplement classroom reading. The Reading Teacher, 66(4), 340-344.

Brown, P. (2018). A Guide for Bringing the SAMR Model to iPads - EdSurge News. Retrieved May 5, 2019, from https://www.edsurge.com/news/2015-02-06-a-guidefor-bringing-the-samr-model-to-ipads.

Brozo, W. G. (2010). To be a boy, to be a reader: Engaging teen and preteen boys in active literacy / William G. Brozo. Newark, Del.: International Reading Association, c2010.

Brozo, W. G., Sulkunen, S., Shiel, G., Garbe, C., Pandian, A., \& Valtin, R. (2014). Reading, Gender, and Engagement. Journal of Adolescent \& Adult Literacy, 57(7), 584-593.

Calvert, H. (2015). Letting Go Of Stand-alone Technology: How to Blend Technology Into Literacy Stations. The Reading Teacher, 69(2), 147-155. Retrieved from http://www.jstor.org/stable/24575042.

Carnahan, C. R., Williamson, P. S., Hollingshead, A., \& Israel, M. (2012). Using Technology to Support Balanced Literacy for Students with Significant Disabilities. Teaching Exceptional Children, 45(1), 20-29. 
Carnevale, A. P., Smith, N., Stone, J. R. III, Kotamraju, P., Steuernagel, B., \& Green, K. (2011, November). Career clusters: Forecasting demand for high school through college jobs, 2008-2018. Washington, DC: Georgetown University Center on Education and the Workforce.

Castek, J., Bevans-Mangelson, J. \& Goldstone, B. (2006). Children's Books: Reading Adventures Online: Five Ways to Introduce the New Literacies of the Internet through Children's Literature. The Reading Teacher, (7), 714. doi:10.1598/RT.59.7.12.

Caudle, S. L. (2004). Qualitative data analysis. In J.S. Wholey, H. P. Hatry, \& K. E. Newcomer (Eds.), Handbook of practical program evaluation ( $2^{\text {nd }}$ ed.)(p. 417-438). San Francisco: Jossey-Bass.

Chen, P, Lambert, A., \& Guidry, K. (2010). Engaging online learners: The impact of web-based Technology on college student engagement. Computers \& Education, $54(4), 1222-12232$.

Chou, C. C., Block, L., \& Jesness, R. (2014). Strategies and Challenges in iPad Initiative. International Association for the Development of the Information Society.

Ciampa, K. (2012). Reading in the digital age: Using electronic books as a teaching tool for beginning readers. Canadian Journal of Learning and Technology, 38(2), 1-26.

Clark, W., \& Luckin, R. (2013). What the research says. iPads in the classroom. London Knowledge Lab, Institute of Education University of London.

Cochrane, T., \& Bateman, R. (2010). Smartphones give you wings. Pedagogical affordances of mobile Web 2.0. Australasian Journal of Education Technology, 26 (1), 1-14 
Cobcroft, R. S., Towers, S., Smith, J., \& Bruns, A. (2006) Mobile learning in review:

Opportunities and challenges for learners, teachers, and institutions. In Proceedings Online Learning and Teaching (OLT) Conference 2006, 21-30.

Coiro, J. (2003). Reading comprehension on the Internet: Expanding our understanding of reading comprehension to encompass new literacies. The Reading Teacher, 56(5), 45864.

Coiro, J. (2005). Making sense of online text. Educational Leadership, 63(2), 30.

Coiro, J. (2012). Understanding dispositions toward reading on the Internet. Journal of Adolescent \& Adult Literacy, 55(7), 645-648.

Coiro, J., \& Moore, D. W. (2012). New literacies and adolescent learners: An interview with Julie Coiro. Journal of Adolescent \& Adult Literacy, 55(6), 551-553.

Coiro, J., Sekeres, D. C., Castek, J., \& Guzniczak, L. (2014). Comparing the quality of third, fourth, and fifth graders' social interactions and cognitive strategy use during structured online inquiry. Journal of Education, 194(2), 1-15.

Creswell, J. (2014). Research Design: Qualitative, Quantitative and Mixed Methods Approached. (4th ed.). Sage Publication Inc., Thousand Oaks, CA.

Crichton, S., Pegler, K., \& White, D. (2012). Personal Devices in Public Settings: Lessons Learned from an iPod Touch/iPad Project. Electronic Journal of E-Learning, 10(1), $23-31$.

Dale, C. (2008). iPods and creativity in learning and teaching: An instructional perspective. International Journal of Teaching and Learning in Higher Education, 20(1), 1-9 
Dana, N.F., Dana, T. M., Kelsay, K.L., Thomas, D., \& Tippins, D. J. (1992 January). Qualitative interviewing and the art of questioning: Promises, possibilities, problems, and pitfalls. Paper presented at the meeting of the Qualitative Research in Education Conference, Athens, GA.

Dayter, D. (2011). Twitter as a means of class participation: Making student reading visible. Journal of Applied Linguistics \& Professional Practice, 8(1), 1-21.

Demirbilek, M. (2010). Investigating attitudes of adult educators towards educational mobile media and games in eight European countries. Journal of Information Technology Education, 9, 235-247.

Dilley, P. (2000). Conducting successful interviews: tips for intrepid research. Theory into Practice, (3), 131. doi:10.2307/1477544.

Eichenlaub, N., Gabel, L., Jakubek, D., McCarthy, G., \& Wang, W. (2011). Project iPad. Computers in Libraries, 31(7), 17-21.

El-Hussein, M. \&Cronje, J. C. (2010). Defining mobile learning in higher education landscape. Journal of Educational Technology \& Society, 13(3), 12-21.

Fellows, R \& Liu, A. (2008) "Research methods for construction” John Wiley \& Sons.

Flowerday, T. \& Schraw, G. (2000). Teacher beliefs about instructional choice: A phenomenological study. Journal of Educational Psychology, 92(4), 634.

Francis, R. W. (2012). Enhancing Teaching and Learning through the Integration of Blended Learning Instructional Strategies (BLIS) in the Classroom. Journal of Applied Learning Technology, 2(2), 6-12. 
Frey, N., Fisher, D., \& Lapp, D. (2015). iPad Deployment in a Diverse Urban High School: A Formative Experiment. Reading \& Writing Quarterly: Overcoming Learning Difficulties, 31(2), 135-150.

Gambrell, L., Palmer, B. Codling, R., \& Mazzoni, S. (1996). Assessing motivation to read. The Reading Teacher, 49(7), 518.

Gee, J. P. (1996) Social Linguistics and Literacies: Ideology in Discourses. $2^{\text {nd }}$ edition. London: Falmer.

Gee, J. P., \& Levine, M. H. (2009). Welcome to Our Virtual Worlds. Educational Leadership, 66(6), 48.

Grant, M., Tamim, S., Brown, D., Sweeney, J., Ferguson, F., \& Jones, L. (2015). Teaching and Learning with Mobile Computing Devices: A Case Study in K-12 Classrooms. Techtrends: Linking Research \& Practice to Improve Learning, 59(4), 32-45.

Hailikari, K. \& Parpala, A. (2014). What impedes or enhances my studying? The interrelation between approaches to learning, factors influencing study progress and earned credits. Teaching in Higher Education, 19(7), 812-824.

Hamilton, E., Rosenberg, J., \& Akcaoglu, M. (2016). The Substitution Augmentation Modification Redefinition (SAMR) Model: a Critical Review and Suggestions for its Use. TechTrends: Linking Research \& Practice to Improve Learning, 60(5), 433-441. https://doi-org.libproxy.lib.ilstu.edu/10.1007/s11528-016-0091-y

Hastings, J. (2013). Gobstopper and Subtext rev up reading. School Library Journal, 59(4), 11. Hilton, J. T. (2016). A Case Study of the Application of SAMR and TPACK for Reflection on Technology Integration into Two Social Studies Classrooms. Social Studies, 107(2), 68. 
Hixon, E., \& Buckenmeyer, J. (2009). Revisiting Technology Integration in Schools: Implications for Professional Development. Computers in the Schools, 26(2), 130-146.

Hou, J., Rashid, J. \& Lee, K. (2017). Cognitive map or medium materiality? Reading on paper and screen. Computers In Human Behavior [serial online]. 67:84-94. Available from: ScienceDirect, Ipswich, MA. Accessed December 12, 2017.

Howard, N., \& Howard, K. (2017). Using tablet technologies to engage and motivate urban high school students. International Journal of Educational Technology, 4(2), 66-74.

Hutchison, A., Beschorner, B., \& Schmidt-Crawford, D. (2012). Exploring the use of the iPad for literacy learning. The Reading Teacher, 66(1), 15-23.

Illinois Report Card. (2018-9). Illinois State Board of Education, Retrieved Aug. 10, 2019.

Jahnke, I., Bergström, P., Lindwall, K., Mårell-Olsson, E., Olsson, A., Paulsson, F., \& Vinnervik, P. (2012). Understanding, Reflecting and Designing Learning Spaces of Tomorrow. Proceedings of the IADIS International Conference Mobile Learning 2012, ML 2012.

Johnson, D. (2013). Teaching above the line. Educational Leadership, 71(4), 84.

Joseph, N. (2008). "Preparing secondary students for 21 st century literacy through content-area reading instruction." Language Arts Journal of Michigan, 23(2), 54-60.

Kalonde, G. (2017). Technology Use in Rural Schools: A Study of a Rural High School Trying to Use iPads in the Classroom. Rural Educator, 38(3), 27-38. Retrieved from http://search.ebscohost.com/login.aspx?direct=true \&db=ofs\&AN=126936974\&site=ehos t-live.

Kellner, D. (2004) Technological Transformation, Multiple Literacies, and the Re-visioning of Education, ELearning, 1(1), pp. 9-37. 
Kimmel, S. C. (2012). Deep reading: Using technology to engage, connect, and share. Library Media Connection, 30(5), 10-12.

Kirkland, D. E. (2011). Books like clothes: Engaging young black men with reading. Journal of Adolescent \& Adult Literacy, 55(3), 199-208. doi:10.1002/JAAL.00025

Lamb, A. (2011). Reading Redefined for a Transmedia Universe. Learning \& Leading with Technology, 39(3), 12-17.

Lankshear, C., and Knobel, M. (2006). New literacies. [Electronic resource]: Everyday practices and classroom learning. Maidenhead; New York : Open University Press, 2006.

Larson, L. C. (2010). Digital readers: The next chapter in e-book reading and response. The Reading Teacher, 64(1), 15-22.

Laverick, D. M. (2014). Supporting striving readers through technology-based instruction. Reading Improvement, 51(1), 11-19.

Lee, J. H., \& Kim, H. (2014). An Exploratory Study on the Digital Identity Formation of Korean University EFL Learners. English Teaching: Practice and Critique, 13(3), 149-172.

Lei, J., \& Zhao, Y. (2008). One-to-one computing: What does it bring to schools? Educational Computing Research, 39(2), 97-122.

Leu, D. J., Jr. (2001). Internet project: Preparing students for new literacies in a global village. The Reading Teacher, 54, 568-585.

Leu, D. J., Jr., Kinzer, C. K., Coiro, J., \& Cammack, D. (2004). Toward a theory of new literacies emerging from the Internet and other information and communication technologies. In R.B.Ruddell \& N.J. Unrau (Eds.), Theoretical models and processes of reading (5th ed., pp. 1570-1613). Newark, DE: International Reading Association. 
Lincoln, Y. S., \& Guba, E. G. (1985). Naturalistic inquiry. Thousand Oaks, CA: Sage.

Lincoln, Y. S., \& Guba, E. G. (1986). But is it rigorous? Trustworthiness and authenticity in naturalistic evaluation. In J. S. Stark \& A. Thomas (Eds.), Assessment \& Program Evaluation ASHE Reader Series (651-658). Boston: Pearson.

Liu, A. (2006). Print vs. electronic resources: A study of user perceptions, preferences, and use. Information Processing and Management, 42 (2), 583-592.

Marshall, C. \& Rossman, G. (1989). Designing qualitative research. Newbury Park, CA: Sage. McClanahan, B., Williams, K., Kennedy, E., \& Tate, S. (2012). A breakthrough for Josh: How use of an iPad facilitated reading improvement. Techtrends: Linking Research \& Practice to Improve Learning, 56(4), 20-28.

Merisuo-Storm, T. (2006). Girls and boys like to read and write different texts. Scandinavian Journal of Educational Research, 50(2), 111-125.

Merisuo-Storm, T., \& Soininen, M. (2014). Interesting Reading Materials and Exercises Encourage Also Reluctant Boys to Read. Procedia - Social and Behavioral Sciences, 116(5th World Conference on Educational Sciences), 2583-2588.

Merriam, S. B. (2009). Qualitative research: A guide to design and implementation. San Francisco, CA: Jossey-Bass.

Millard, E. E. (1997). Differently literate: Gender identity and the construction of the developing reader. Gender and Education 9(1), 31-48.

Montelongo, J. J. \& Herter, R. (2010). Using technology to support expository reading and writing in science classes. Science Activities, 47(3), 89.

Penrod, D. (2007). Using blogs to enhance literacy: The next powerful step in 21st-century learning / Diane Penrod. Lanham, Md.: Rowman \& Littlefield Education, 2007. 
Piaget, J. (1964). “Development and Learning”. In R.E. Ripple \& V.N. Rockcastle (eds.), Piaget Rediscovered: Report of the Conference on Cognitive Studies and Curriculum Development, 7-20. Ithaca: Cornell University.

Portnoy, L. (2018). How SAMR and Tech Can Help Teachers Truly Transform Assessment EdSurge News. Retrieved from https://www.edsurge.com/news/2018-0201-how-samr-and-tech-can-help-teachers-truly-transform-assessment

Prensky, M. (2001). Digital Natives, Digital Immigrants Part 1. On The Horizon, 9(5), 1. doi:10.1108/10748120110424816lkj;1

Puente, K. (2012). Empowering students with digital reading. District Administration, 39.

Puentedura, R. R. (2006). Transformation, technology, and education in the state of Maine [Web log post]. Retrieved from http://www.hippasus.com/rrpweblog/archives/2006_11.html.

Puentedura, R.R. (2009). SAMR and Bloom's Taxonomy: Assembling the Puzzle. Retrieved from https://www.commonsense.org/education/articles/samr-and-blooms-taxonomyassembling-the-puzzle.

Purcell, K., Heaps, A., Buchanan, J. \& Friedrich, L. (2013). "How Teachers Are Using Technology at Home and in Their Classrooms" Pew Research Center, Washington, D.C. http://www.pewinternet.org/2013/02/28/how-teachers-are-using-technology-at-homeand-in-their-classrooms/.

Ragen, M. (2012). Inspired technology, inspired readers: How book trailers foster a passion for reading. Access 26 (1) 8-13.

Romrell, D., Kidder, L. \& Wood, E. (2014). The SAMR Model as a Framework for Evaluating mLearning. Online Learning Journal, 18(2), Retrieved August 11, 2019 from https://www.learntechlib.org/p/183753/. 
Rossing, J. P., Miller, W. M., Cecil, A. K., \& Stamper, S. E. (2012). iLearning: The Future of Higher Education? Student Perceptions on Learning with Mobile Tablets. Journal of the Scholarship of Teaching and Learning, 12(2), 1-26.

Rowsell, J. (2014). Toward a phenomenology of contemporary reading. Australian Journal of Language \& Literacy, 37(2), 117-127.

Rowsell, J. \& Walsh, M. (2011). Rethinking Literacy Education in New Times: Multimodality, Multiliteracies, \& New Literacies. Brock Education: A Journal of Educational Research and Practice, (1).

Saldaña, J. (2009). The coding manual for qualitative researchers / Johnny Saldaña. Los Angeles: SAGE, 2009.

Schrock, K. (2013). SAMR and Bloom's. Retrieved from https://www.schrockguide.net/samr.html.

Sheppard, D. (2011). Reading with iPads - the difference makes a difference. Education Today, August 12-15.

Sloan, R. H. (2012). Using an e-Textbook and iPad: Results of a Pilot Program. Journal of Educational Technology Systems, 41(1), 87-104.

Smith, M. W. (2011). IPads for every high school student in Michigan district. Retrieved from http://www.usatoday.com/tech/news/story/2011-09-20/schools-education- ipadstudents/50480836/1.

Smith, M. W. \& Wilhelm, J. D. (2002). Reading don't fix no Chevys: Literacy in the lives of young men. Portsmouth, NH: Heinemann, 2002. 
Spires, H.A. \& Estes, T.H. (2002). Reading in web-based learning environments. In C.C. Block \& M. Pressley (Eds.), Comprehension instruction: Research-based best practices (pp. 115-125). New York: Guilford.

Spires, H., Bartlett, M. E., Garry, A., \& Quick, A. H. (2012). Literacies and learning: Designing a path forward. Raleigh, NC: Friday Institute for Educational Innovation at North Carolina State University. Retrieved from https://www.fi.ncsu.edu/wp-content/uploads/ 2019/08/digital-literacies-and-learning.pdf.

Stassen, W. (2010). Your news in 140 characters: Exploring the role of social media in journalism. Global Media Journal: African Edition, 4(1), 1-16.

Strauss, A. \& Corbin, J (1998). Basics of qualitative research: Techniques and procedures for developing grounded theory ( $2^{\text {nd }}$ ed.) Thousand Oaks: Sage.

Street, B. V. (2001). Literacy and development: Ethnographic perspectives / edited by Brian V. Street. London; New York: Routledge, 2001.

Sutherland, O., Breen, A., \& Lewis, S. P. (2013). Discursive narrative analysis: A study of online autobiographical accounts of self-injury. The Qualitative Report, 18(95), 1-17.

Tapscott, D. (1998). Growing up digital: The rise of the net generation. United States of America: McGraw-Hill.

Thoermer, A., \& Williams, L. (2012). Using digital texts to promote fluent reading. Reading Teacher, 65(7), 441-445.

Thomas, M.J.W. (2002). Learning within Incoherent Structures: The Space of Online Discussion Forums. Journal of Computer Assisted Learning 18(3): 351-366.

Valenza, J., \& Stephens, W. (2012). Reading Remixed. Educational Leadership, 69(6), 75-78. 
van Wyk, G., \& Louw, A. (2008). Technology-Assisted Reading for Improving Reading Skills for young South African Learners. Electronic Journal of E-Learning, 6(3), 245.

Vygotsky, L., Hanfmann, E. \& Vakar, G. (1962). Thought and language. [Electronic resource]. Cambridge, Mass.: MIT Press, 1962.

Walsh, M., Asha, J. \& Sprainger, N. (2007). Reading digital texts. Australian Journal of Language \& Literacy, 30(1), 40-53.

Wang, M., Shen, R., Novak, D. \& Pan, X. (2009). The impact of mobile learning on students' learning behaviours and performance: Report from a large blended classroom. British Journal of Education Technology, 40(4), 673-695.

Ward, N. D., Finley, R. J., Keil, R. G., \& Clay, T. G. (2013). Benefits and Limitations of iPads in the High School Science Classroom and a Trophic Cascade Lesson Plan. Journal of Geoscience Education, 61(4), 378-384. Retrieved from https://search-ebscohost-com.libproxy.lib.ilstu.edu/login.aspx?direct=true \&db=eric\&AN $=\mathrm{EJ} 1163981 \&$ site $=$ eds-live $\&$ scope $=$ site.

Warschauer, M. (2006). Laptops and literacy: Learning in the wireless classroom. New York, NY: Teachers College Press.

Warschauer, M., \& Tate, T. (2015). Going one-to-one, 2.0. Educational Leadership, 72(8), 60.

Welch, M. (2010). Instructional technological factors that impede and impel struggling adolescent students' reading comprehension. International Journal of Technology, Knowledge \& Society, 6(4), 137-150.

Wenglinsky, H. (1998). Does It Compute? The Relationship between Educational Technology and Student Achievement in Mathematics. Educational Testing Service. Princeton, NJ. 
Wetzel, K., Zambo, R., \& Ryan, J. (2007). Contrasts in classroom technology use between beginning and experienced teachers. International Journal of Technology in Teaching and Learning, 3(1), 15-27.

White, B. (2007). Are girls better readers than boys? Which boys? Which girls? Canadian Journal of Education, 30(2), 554-581.

Wright, S., Fugett, A., \& Caputa, F. (2013). Using e-readers and Internet resources to support comprehension. Journal of Educational Technology \& Society 16(1), 367-379.

Yin, R. K. (2003). Case study research: Design and methods (3rd ed.). Thousand Oaks, CA: Sage. 


\section{APPENDIX A: RECRUITMENT EMAIL}

Dear Student,

I am a doctoral student at Illinois State University. I am currently working under Dr. Robyn Seglem in the School of Teaching and Learning. I am conducting research to examine student perception of iPad use among high school students.

You have been randomly selected to participate in this study. I am requesting your participation, which will involve two audio-taped interviews with me that will take place in a location convenient to you. I expect each interview to last approximately 30-45 minutes. The questions will relate to your thoughts and interests about using the iPad. . In addition, your participation will also include one observation of you in class using your iPad.

Your participation is completely voluntary. If you would like to be a part of this research study, please complete the student assent form (attached to this email), and have a parent or guardian complete the parental consent form (also attached). You will need to send these forms back to me in order to be considered for participation. Once I receive these forms, I will email you within a week to let you know if you have been selected as a participant. I will then set up a convenient time to meet at your school for the first interview.

Thank you very much for your time and interest in this study. Your opinions will be invaluable to the success of this research study.

Sincerely,

Mrs. Susan E. Hess

If you have any questions about your rights as a subject/participant in this research, or if you feel you have been placed at risk, you can contact the Research Ethics \& Compliance Office at Illinois State University at (309) 438-8451. 


\section{APPENDIX B: PARENTAL PERMISSION}

\section{Dear Parent or Guardian,}

I am a doctoral student under the direction of Dr. Robyn Seglem in the School of Teaching and Learning at Illinois State University. I am conducting a research study to examine student use of iPads among high school students. The study also seeks to find out how the one-to-one iPad initiative has impacted high school students for their literacy practices. I am requesting your child's participation, which will involve two audio-taped interviews with me that will take place in the school at a location that is convenient to your student. I expect the interviews to last approximately 30-45 minutes each and will not take your student out of an academic class. The interview will be audio taped, with your permission. The study will also include an observation of your student in a class in which the student uses the iPad. The teacher of the class will not know that your student is being observed in order to preserve the confidentiality of the student's participation in the study.

Your child's participation in this study is voluntary. If your child chooses not to participate or to withdraw from the study at any time, there will be no penalty of any kind. Your child's decision to participate or not to participate will not affect his/her employment in any way or grades in his/her current or future courses. The results of the study will be used in a written report known as a dissertation and oral presentation, but your child's name will never be used. I will take all precautions to maintain your child's confidentiality, and pseudonyms will be used during the interview and in the final report.

There are minimal physical, psychological, or social risks to this research study. The risks include anxiety and exposure to the activities, but every effort will be made to make your child feel comfortable, and a level of confidentiality will be provided to help minimize these risks. Please be assured that no information that your child reveals in the interview regarding the use of iPads for literacy will be given to teachers or administrators. However, if information shared reveals inappropriate use according to the district's Acceptable Use Policy, the researcher will notify the schools' administrators. The study is not seeking this type of information nor will questions be asked about these issues. To minimize risk, interviews will be conducted in settings that provide the maximum amount of privacy and confidentiality to your child at your child's school during a free period or lunch hour so no class time will be lost. In addition, your student's participation will not affect their grades in school, courses, future courses or their standing at school. Finally, your child has the right to refuse to answer any questions during the interview.

Although small, the possible benefit of your child's participation would be to reflect upon his/her own experiences and to assist in identifying ways to improve the use of iPads for literacy practices and to understand the impact that high school students feel about their use in our schools. Please sign and return this form to me at sehess@ilstu.edu in order for your student to participate.

If you have any questions concerning the research study, please call me at (224) 653-3240, or Dr. Robyn Seglem at (309) 438-3969. 
Sincerely,

Susan E. Hess

sehess@ilstu.edu

I give permission for my child to participate in the above study and be audio taped.

Your child's name

Your signature

Your printed name
Date

Relationship

Date

If you have any questions about your rights as a subject/participant in this research, or if you feel you have been placed at risk, you can contact the Research Ethics \& Compliance Office at Illinois State University at (309) 438-2529. 


\section{APPENDIX C: INFORMED ASSENT}

\section{Dear Student,}

I am a graduate student studying under Dr. Robyn Seglem in the School of Teaching and Learning at Illinois State University. I am leading a research study to look at the impact of the one-to-one iPad program on high school students for their literacy practices. The study will also try to find out how students feel about the use of iPads for their reading engagement. I would like your participation, which will involve two audio-taped interviews with me that will take place at school in a location convenient to you. I expect each interview to last approximately 30 45 minutes each. The interview will be audio taped, with your permission. The study will also include an observation of you in a class in which you use the iPad. The teacher of the class will not know that you are the student being observed to keep your participation confidential.

Your participation in this study is completely optional. If you choose not to participate or to withdraw from the study at any time, there will be no penalty of any kind. Your decision to participate or not to participate will not affect your employment in any way or grades in your current or future classes. I will use the results of the study in a written report and oral presentation, it will be used for a dissertation study, but your name will never be used. I will take keep your identity a secret by using a fake name in the reports and during the interviews. This will help to keep your identity hidden so that information you share with me will remain confidential and not connected to you.

There are minimal risks to this research study. The risks include anxiety and exposure to the activities, but every effort will be made to make you feel comfortable, and a level of confidentiality will be provided to help minimize these risks. Please be confident that no information that you reveal in the interview will be given to teachers or administrators unless the information violates the Acceptable Use Policy. In that case, I would be forced to notify administrators per this school policy. However, the study is not seeking this type of information nor will questions be asked about these issues. To minimize risk, interviews will be done in settings at school that provide the maximum amount of privacy that will keep your identity a secret. The interviews will also be scheduled during a free period or lunch hour so that not class time will be lost. In addition, your participation will not affect your grades or standing at school. Finally, you have the right to refuse to answer any questions during the interview.

Although small, the possible benefit of your participation would be to reflect upon your own experiences and to help me identify ways to improve the use of iPads in our schools. If you choose to participate, please have a parent or guardian sign and return via email the parent permission form to sehess@ilstu.edu. In addition, you will need to sign and bring this form with you to our first meeting.

If you have any questions concerning the research study, please call me at (224) 653-3240, or Dr. Robyn Seglem at (309) 438-3969.

Sincerely, 
Susan E. Hess

sehess@ilstu.edu

I give permission to participate in the above study.

Signature

Date

I give permission for my interview to be audiotaped.

Signature

Date

If you have any questions about your rights as a subject/participant in this research, or if you feel you have been placed at risk, you can contact the Research Ethics \& Compliance Office at Illinois State University at (309) 4382529. 


\section{APPENDIX D: STUDENT CONSENT (18 YEARS \& OLDER)}

\section{Dear Student,}

I am a doctoral student under the direction of Dr. Robyn Seglem in the School of Teaching and Learning at Illinois State University. I am conducting a research study to examine student use of iPads among high school students. The study also seeks to find out how the one-to-one iPad initiative has impacted high school students for their literacy practices. I am requesting your participation, which will involve two audio-taped interviews with me that will take place in the school at a location that is convenient to you. I expect the interviews to last approximately 30-45 minutes each and will not take you out of an academic class. The interview will be audio taped, with your permission. The study will also include an observation of you in a class that uses the iPad. The teacher of the class will not know that you are being observed which will help to preserve the confidentiality of your participation in the study.

Your participation in this study is voluntary. If you choose not to participate or to withdraw from the study at any time, there will be no penalty of any kind. Your decision to participate or not to participate will not affect your employment in any way or grades in your current or future courses, and your standing in school will not be affected. The results of the study will be used in a written report known as a dissertation and an oral presentation, but your name will never be used. I will take all precautions to maintain your confidentiality, and pseudonyms will be used during the interview and in the final report.

There are minimal physical, psychological, or social risks to this research study. The risks include anxiety and exposure to the activities, but every effort will be made to make you feel comfortable, and a level of confidentiality will be provided to help minimize these risks. Please be assured that no information that you reveal in the interview regarding the use of iPads for literacy will be given to teachers or administrators. However, if information shared reveals inappropriate use according to the district's Acceptable Use Policy, the researcher will notify the schools' administrators. The study is not seeking this type of information nor will questions be asked about these issues. To minimize risk, interviews will be conducted in settings that provide the maximum amount of privacy and confidentiality to you at your school during a free period or lunch hour so no class time will be lost. Finally, you have the right to refuse to answer any questions during the interview.

Although small, the possible benefit of your participation would be to reflect upon your own experiences and to assist in identifying ways to improve the use of iPads for literacy practices and to understand the impact that high school students feel about their use in our schools. Please sign, date, and return this form to me at sehess@ilstu.edu in order to participate in the study.

If you have any questions concerning the research study, please call me at (224) 653-3240, or Dr. Robyn Seglem at (309) 438-3969.

Sincerely, 
Susan E. Hess

sehess@ilstu.edu

I give permission to participate in the above study and be audio taped.

Your signature

Your printed name

Date

If you have any questions about your rights as a subject/participant in this research, or if you feel you have been placed at risk, you can contact the Research Ethics \& Compliance Office at Illinois State University at (309) 438-2529. 


\section{APPENDIX E: INTERVIEW QUESTIONS}

Demographic information will be solicited.

Interview questions

1. Can you tell me about any particular websites or apps you have used that have allowed you to express your opinions or experiences? (identity)

2. Tell me about a time when you created something on the iPad. What was it? (engagement)

3. How have you used the iPad to explore your own interests? (identity)

4. Tell me what a typical week looks like using your iPad? (engagement-holistic experience)

5. Tell me about a time when you used the iPad to collaborate with other students? (community-creative production)

6. Give me an example of how the iPad has helped you to express yourself in a more meaningful way? (engagement/identity)

7. Tell me about a time you wished you could have used the iPad for class. (engagement)

8. Explain a time when you used the iPad to communicate with someone about school. May be either teacher or another student (community/foster communication and sharing)

9. Is there anything that you would like to share about your iPad experiences that we have not already discussed? 